Research Article

\title{
Xiaoxuming Decoction Regulates Vascular Function by Modulating G Protein-Coupled Receptors: A Molecular Docking Study
}

\author{
Yanjia Shen $\mathbb{D}^{1},{ }^{1}$ Ran Yang $\mathbb{D}^{1},{ }^{1}$ Rui Zhou, ${ }^{1,2}$ Wendan Lu, ${ }^{1}$ Li Li $\mathbb{D}^{1},{ }^{1}$ Ziran Niu, ${ }^{1,3}$ \\ Miao Chen $\left({ }^{1},{ }^{1}\right.$ Jinhua Wang $\left(1,{ }^{1}\right.$ Yuehua Wang, ${ }^{1}$ Lianhua Fang $\odot,{ }^{1}$ and Guanhua Du $\left({ }^{1}\right.$ \\ ${ }^{1}$ Beijing Key Laboratory of Drug Targets Identification and Drug Screening, Institute of Materia Medica, Chinese Academy of Medical \\ Sciences and Peking Union Medical College, Beijing, China \\ ${ }^{2}$ Biomedical Engineering Research Center, Kunming Medical University, Kunming, China \\ ${ }^{3}$ Department of Pharmacy, Peking Union Medical College Hospital, Chinese Academy of Medical Sciences and Peking Union \\ Medical College, Beijing, China
}

Correspondence should be addressed to Li Li; lili@imm.ac.cn, Lianhua Fang; fanglh@imm.ac.cn, and Guanhua Du; dugh@imm.ac.cn

Received 17 January 2021; Revised 3 April 2021; Accepted 28 May 2021; Published 7 June 2021

Academic Editor: Liang-Liang Zhu

Copyright (c) 2021 Yanjia Shen et al. This is an open access article distributed under the Creative Commons Attribution License, which permits unrestricted use, distribution, and reproduction in any medium, provided the original work is properly cited.

\begin{abstract}
Xiaoxuming decoction (XXMD) is a traditional Chinese herbal medicine (CHM) that is used for the treatment of stroke in China. Stroke injury damages the cerebral vasculature and disrupts the autoregulation of vasoconstriction and vasodilatation, which is crucial for maintaining constant cerebral blood flow (CBF). It has been reported that XXMD exerts a positive effect on cerebral circulation in animal models of stroke. However, the mechanisms underlying the regulatory effect of XXMD on vascular tone, and the interactions among the multiple components of XXMD, remain unclear. In this study, XXMD was found to induce relaxation of the basilar artery rings of rats precontracted by 5-hydroxytryptamine (5-HT) in vitro, in a dose-dependent manner. The modulation of vascular tone and the process of cerebral ischemia are mediated via the interactions between $G$ protein-coupled receptors (GPCRs) and their ligands, including 5-HT, angiotensin II (Ang II), and urotensin II (UII). Thus, the potential synergistic effects of the different components of XXMD on the regulation of vasoconstriction and vasodilation were further investigated by molecular docking based on network pharmacology. We constructed and analyzed a database comprising 963 compounds of XXMD and studied the interactions between five vascular GPCRs (5-HT1A receptor (5-HT1AR), 5-HT1B receptor (5-HT1BR), Ang II type 1 receptor (AT1R), beta 2-adrenergic receptor ( $\beta 2$-AR), and UII receptor (UTR)) and the various herbal constituents of XXMD using molecular docking. By constructing and analyzing the compound-target networks of XXMD, we found that Glycyrrhizae Radix et Rhizoma, Ginseng Radix et Rhizoma, and Paeoniae Radix Alba were the three major herbs that contained a large number of compounds with high docking scores. We additionally observed that several constituents of XXMD, including gallotannin, liquiritin apioside, nariutin, 1,2,3,4,6-pentagalloylglucose, folic acid, and ginsenoside Rb1, targeted multiple vascular GPCRs. Moreover, the interactions between the components of XXMD and the targets related to vascular tone constituted the comprehensive cerebrovascular regulatory function of XXMD and provided a material basis of the vasoregulatory function of XXMD. The study reports the contributions of various components of XXMD to the regulatory effects on vascular tone and provides scientific evidence for the multicomponent and multitargeting characteristics of XXMD.
\end{abstract}

\section{Introduction}

Xiaoxuming decoction (XXMD) is a well-known traditional Chinese herbal medicine (CHM), which was recorded in Beiji
Qianjin Yaofang, written by Sun Simiao of the Tang Dynasty, and has been widely used for over centuries in China to treat strokes in clinics [1]. This formula consists of twelve Chinese herbs, including Scutellariae Radix, Paeoniae Radix Alba, 
Glycyrrhizae Radix et Rhizoma, Stephaniae Tetrandrae Radix, Ginseng Radix et Rhizoma, Cinnamomi Ramulus, Armeniacae Semen Amarum, Ephedrae Herba, Chuanxiong Rhizoma, Aconiti Lateralis Radix Praeparata, Saposhnikoviae Radix, and Zingiberis Rhizoma Recens at a $1: 1: 1: 1: 1: 1: 1$ : $1: 1: 1: 1.5: 5$ ratio. Preclinical studies from our laboratory and other groups have demonstrated that XXMD has neuroprotective effects in rats with acute or chronic cerebral ischemia [2-10]. The anti-ischemic activity of XXMD is mediated via numerous mechanisms, including the inhibition of oxidative stress [2], reduction of neuronal apoptosis [3], preservation of mitochondrial integrity and improvement of mitochondrial function $[4,5]$, reduction in the activity of inducible nitric oxide synthase (iNOS) in cerebral tissues [6], alleviation of blood-brain barrier (BBB) disruption [7], protection of the neurovascular unit [8], suppression of astrocyte activation [9], and regulation of the expression of differentially expressed proteins in the hippocampus [10]. Notably, a meta-analysis of eight randomized controlled trials (RCTs) published between 1992 and 2012 revealed that XXMD improves neurological deficits and is safe in patients with acute ischemic stroke when compared to Western conventional medicine (WCM), which was used as the control [1]. However, the mechanisms underlying the activity of XXMD in the treatment of stroke remain unclear.

Stroke is a type of acute cerebral vascular disease, which is the leading cause of adult disability and the second most common cause of death worldwide [11]. Stroke occurs when the blood supply to a part of the brain is interrupted, and the brain cells die due to oxygen or nutrient insufficiency. There are two main categories of stroke, namely, ischemic stroke, in which the flow of blood is restricted, and hemorrhagic stroke, which is characterized by bleeding. Ischemia induces cerebral damage, which impairs the vasculature and adversely affects cerebral blood flow (CBF) [12]. As insufficient blood supply is presently considered to be a major pathology of stroke, drugs that induce recovery of the cerebral blood supply are of enormous promise. The drugs that modulate the vascular tone and dilate the cerebral arteries can restore blood supply to the ischemic area and thus provide a material basis for the subsequent antireperfusion injury and neuronal protection.

$\mathrm{G}$ protein-coupled receptors (GPCRs), also known as seven-transmembrane domain receptors, can regulate vascular contraction by activating second messengers, including cyclic adenosine monophosphate (cAMP), inositol trisphosphate $\left(\mathrm{IP}_{3}\right)$, and $\mathrm{Ca}^{2+}[13]$. It is known that 5-hydroxytryptamine (5-HT), angiotensin II (Ang II), and urotensin II (UII) are strong vasoconstrictors and regulate blood pressure. These substances can trigger vasoconstriction by binding to their specific receptors, including 5-HT 1A receptor (5-HT1AR), 5-HT1B receptor (5-HT1BR), Ang II type 1 receptor (AT1R), and UII receptor (UTR) [14-16]. Beta 2-adrenergic receptor ( $\beta 2$-AR) can alter the tension of blood vessels and regulate the release of renin $[17,18]$. Accumulating evidence has demonstrated that both GPCRs and their ligands, including 5-HT, Ang II, and UII, partake in the process of cerebral ischemia [19-21]. XXMD exerts a positive effect on cerebral vasculature and circulation in animal models of stroke $[9,22,23]$. Previous studies

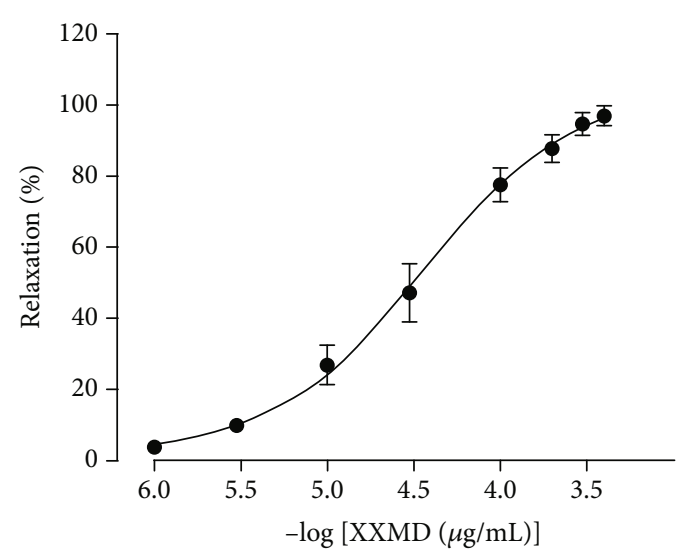

FIgURE 1: Vasorelaxant effects of XXMD on endothelium-intact basilar artery precontracted with 5-HT. The results are presented as the mean \pm standard error of mean (SEM); $n=7$.

have demonstrated that XXMD increases regional CBF in experimental rats with cerebral hemorrhage [24] and also improves the reduction in cerebrovascular reactivity induced by chronic cerebral ischemia in rats [9]. However, the underlying mechanisms and interactions between the constituents of XXMD and vascular GPCRs are yet to be fully understood.

Network pharmacology is based on the theory of systems biology and is used to perform network analysis of biological systems. In network pharmacology, a specific signal node (nodes) can be selected to perform novel analyses of a multitarget drug for molecular design. Network pharmacology can serve as a robust method for studying "drugs-target-disease" networks, which may be closer to elucidating the complex nature of the disease being investigated [25]. To date, network-based methods have been used as a novel strategy for discovering the constituents of traditional Chinese medicine (TCM), identifying bioactive compounds, and elucidating the mechanisms underlying the action of herbal formulae [26]. Molecular docking is a computer-assisted approach that is primarily used to study the interactions between two or several molecules using both geometric complementarity and energy matches. Molecular docking has been widely used in drug discovery and serves as an important tool for the investigation and evaluation of herbal medicines $[27,28]$. The combined use of molecular docking and network pharmacology can provide valuable information and improve the accuracy of the prediction.

Although some progress has been made in the pharmacological investigation of XXMD over the past few years [1-10, 29 ], the interactions among the multiple components of XXMD remain to be elucidated. The investigation of TCM using network pharmacology can aid in the discovery of multiple therapeutic targets for the various active ingredients to formulate effective interactions and therapeutic targets. This approach can be used to identify the targets, the group of active constituents that play a role in the interactions, and the material basis of the active herbal components of XXMD.

In this study, we found that XXMD could induce relaxation of the basilar artery rings of rats precontracted by $5-\mathrm{HT}$ in a dose-dependent manner. However, the mechanism 


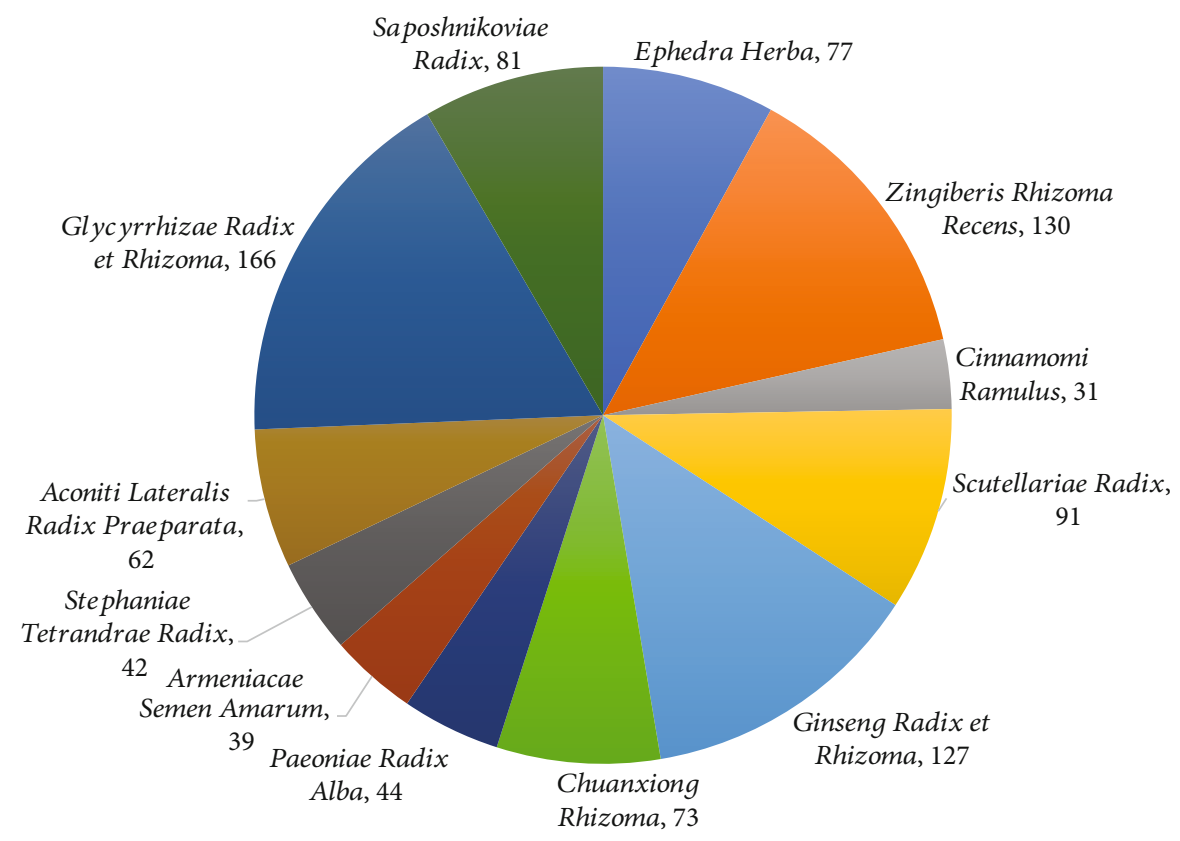

FIgURE 2: Number of compounds in the herbal constituents of XXMD.

underlying the modulation of vascular tone and the material basis of XXMD remain unclear. We performed molecular docking for investigating the potential synergistic effects of the constituents of different herbs in XXMD on the regulation of vascular tone. The interactions between the five GPCRs linked to vasoconstriction (5-HT1AR, 5-HT1BR, AT1R, $\beta 2-A R$, and UTR) and the various herbal constituents of XXMD were assessed. The compound-target networks for XXMD were subsequently constructed and analyzed.

\section{Materials and Methods}

2.1. Preparation of XXMD. All the twelve crude herbs of XXMD were purchased from Beijing Tongrentang Co., Ltd. (Beijing, China). The identification and deposition of these medicinal herbs and the preparation of XXMD were performed by Jiangsu Kanion Pharmaceutical Co., Ltd. (China). Briefly, the crude herbs were soaked in 95\% aqueous ethanol for 2 hours and refluxed in a heated water bath for 1 hour. The filtered and mixed suspensions were collected, and their concentrations were subsequently determined. The extraction was performed thrice using petroleum ether. The fraction eluted with $40 \%$ ethanol and the intermediate layer fraction were incorporated into XXMD [10].

2.2. Preparation of Rat Cerebral Arterial Rings. Male Sprague-Dawley rats, weighing 240-260 g, were provided by Vital River Laboratories (Beijing, China). The animals were housed in plastic cages under controlled humidity and temperature and were exposed to a 12-hour light/dark cycle. The animals had ad libitum access to purified water and a standard diet. Animal care and handling were performed in accordance with the guidelines of the Institutional Animal Care and Use Committee of the Chinese Academy of Medical Science and Peking Union Medical College.
TABLE 1: Classification and number of chemical constituents in XXMD.

\begin{tabular}{lccc}
\hline Classification & Number & Classification & Number \\
\hline Essential oils & 309 & Coumarin & 23 \\
Flavonoids & 232 & Tannins & 16 \\
Alkaloid & 124 & Chromone & 15 \\
Saponin & 69 & Polyacetylene & 14 \\
Phenol and organic acid & 49 & Steroid & 12 \\
Fatty acid and ester & 28 & Others & 44 \\
Glycosides & 28 & In total & 963 \\
\hline
\end{tabular}

The rats were euthanized by cervical dislocation, following which the basilar artery was rapidly isolated and cut into $2 \mathrm{~mm}$ long segments in ice-cold physiological saline solution (PSS) having the following composition (mmol/L): $\mathrm{NaCl} 130$, $\mathrm{KCl} 4.7, \mathrm{MgSO}_{4}$ 1.17, $\mathrm{KH}_{2} \mathrm{PO}_{4} 1.18, \mathrm{NaHCO}_{3}$ 14.9, glucose 5.5 , ethylene diamine tetraacetic acid 0.026 , and $\mathrm{CaCl}_{2} 1.6$. For intact tissue preparation, extreme care was taken to avoid endothelial cell damage. The segments were then mounted on $40 \mu \mathrm{m}$ stainless steel wires in a Multi Myograph System (Danish Myograph Technology, Aarhus, Denmark), and the contractile responses were determined. The organ chamber was filled with $5 \mathrm{~mL}$ of PSS, through which $95 \% \mathrm{O}_{2} / 5 \%$ $\mathrm{CO}_{2}$ was continually bubbled, and the temperature was maintained at $37^{\circ} \mathrm{C}$. The segments of the basilar arteries were normalized to the optimal initial tension, according to the instructions provided with the Multi Myograph System. The segments were then allowed to equilibrate for $60 \mathrm{~min}$ at the resting tension. The PSS was changed every 20 min during equilibration. After equilibration, the arterial rings were constricted twice with a high $\mathrm{K}^{+}(60 \mathrm{mmol} / \mathrm{L})$ PSS (K-PSS) 
having the following composition (mmol/L): $\mathrm{NaCl} 74.7, \mathrm{KCl}$ $60, \mathrm{MgSO}_{4} 1.17, \mathrm{KH}_{2} \mathrm{PO}_{4} 1.18, \mathrm{NaHCO}_{3}$ 14.9, glucose 5.5, ethylene diamine tetraacetic acid 0.026 , and $\mathrm{CaCl}_{2}$ 1.6. The integrity of a functional endothelium was verified by the ability of acetylcholine (Ach) $(20 \mu \mathrm{mol} / \mathrm{L})$ to induce more than $60 \%$ relaxation in the arterial rings precontracted with $60 \mathrm{mmol} / \mathrm{L} \mathrm{K}$-PSS [30].

\subsection{5-HT-Induced Contraction in Isolated Cerebral Arterial} Rings. The basilar arterial rings with intact endothelium were precontracted with $1 \mu \mathrm{mol} / \mathrm{L}$ 5-HT (Sigma). After a sustained contraction was obtained, XXMD was added to the bathing solution in a cumulative manner $(1,3,10,30,100,200,300$, and $400 \mu \mathrm{g} / \mathrm{mL}$ ) to obtain the concentration-response curves.

2.4. Retrieval of the Constituents of XXMD. The chemical constituents of the twelve herbs in XXMD were retrieved from China Natural Product Database (http://pharmdata .ncmi.cn) and from the literature. The chemical structures were drawn using ISIS Draw 2.5 (MDL Information Systems, Inc.).

2.5. Preparation of Ligands and Target Proteins. Five vascular GPCRs (5-HT1AR, 5-HT1BR, AT1R, $\beta 2-A R$, and UTR) were considered for the molecular docking study. The crystal structures of $5-\mathrm{HT} 1 \mathrm{BR}, \mathrm{AT} 1 \mathrm{R}$, and $\beta 2-\mathrm{AR}$ were retrieved from the RCSB Protein Data Bank (PDB) (http://www.pdb .org/) [31], and the PDB codes were 4IAQ, 4YAY, and $4 \mathrm{LDE}$, respectively. The structures of the GPCRs for which crystal structures were unavailable, namely, 5-HT1AR and UTR, were constructed by homology modeling using Discovery Studio 4.1. After sequence comparison, the sequences of $\beta 2-A R$ (PDB ID: 2RH1) and 5-HT1BR (PDB ID: 4IAQ) were selected as the templates for modeling UTR and 5-HT1AR, respectively. The Build Homology Model module in Discovery Studio was used for homology modeling, and the model with optimal reliability was selected for molecular docking.

A ligand library, comprising the different conformations of each ligand, was constructed using the Prepare Ligands tool. The existing ligands and water of crystallization in the target proteins were removed using the Prepare Protein tool. The ligand-receptor binding sites were determined using the Define and Edit Binding Site tool, based on the information obtained from the binding sites of the cocrystallized ligands in the protein structures. For 5-HT1BR and AT1R, the binding sites of the cocrystallized ligands, dihydroergotamine and 5,7-diethyl-1-\{[2' -(1H-tetrazol-5-yl) biphenyl-4-yl $]$ methyl $\}$ 3,4-dihydro-1,6-naphthyridin-2(1H)-one, respectively, were defined as the active ligand-binding pocket. For $\beta 2-\mathrm{AR}$, the binding site of BI167107 was defined as the active ligandbinding pocket.

2.6. Molecular Docking. The LibDock module of Dock Ligands in Discovery Studio 4.1 was used to perform molecular docking. The conformation method was set to fast to ensure docking accuracy and velocity, and the other parameters were set to default. In this semiflexible docking approach, 100 or less conformations of each ligand were generated to ensure computational speed and comprehensiveness. The

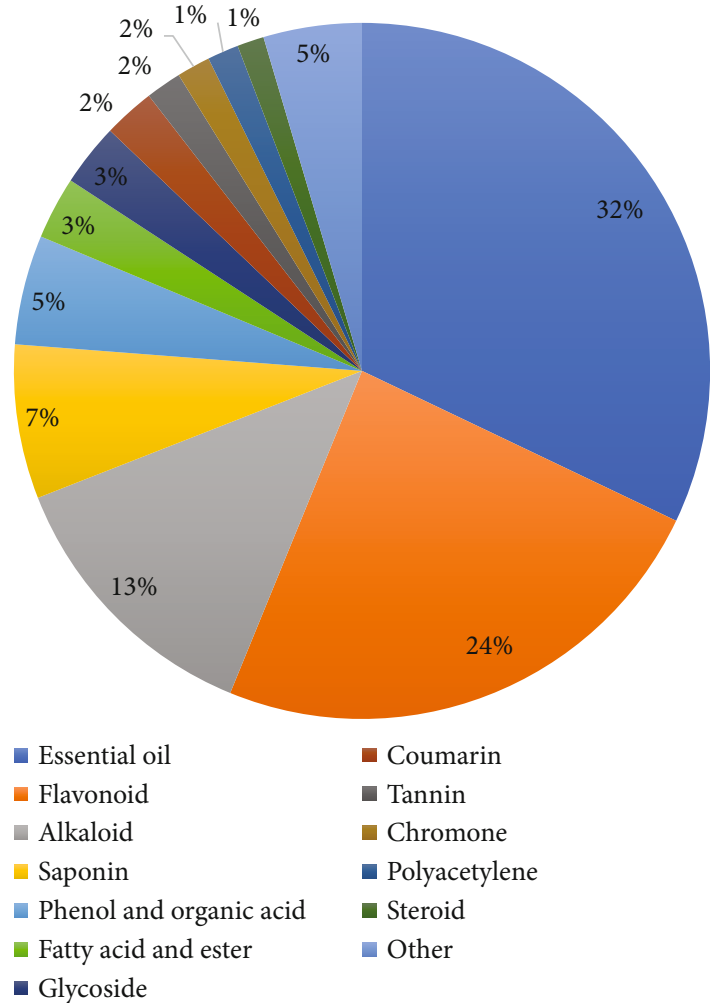

FIGURE 3: Classification and proportion of the chemical constituents of XXMD.

output index and LibDock scores were subsequently obtained. The scores indicate the binding affinity between the receptors and the ligand conformations. The higher the score of a small molecule, the stronger the protein binding affinity. For each target, the 50 top-scoring compounds were selected, and their scores were considered to be the highest among all the conformations for each ligand. The LibDock scores of the agonists and antagonists, retrieved from the IUPHAR database, were also determined for each target, for assessing the potential activity of the herbal compounds in XXMD. The following agonists and antagonists were used for molecular docking: 5-HT1AR (agonists: U92016A, vilazodone, and vortioxetine; antagonists: (S)-UH 301 and WAY-100635); 5-HT1BR (agonists: CP94253, eletriptan, and L-694,247; antagonists: GR-55562 and SB236057); AT1R (agonists: L-162,313; antagonists: candesartan, irbesartan, and valsartan), $\beta 2$-AR (agonists: formoterol, salmeterol, and zinterol; antagonists: carvedilol, propranolol, and timolol; and UTR (agonists: AC-7954 and FL104; antagonists: palosuran and SB-706375).

2.7. Compound-Target Network Construction Using Cytoscape. The information pertaining to the chemical composition and related compound-target network interactions were analyzed using Cytoscape version 3.7.1. The compound-target network was established using Cytoscape, and the interactions were subsequently visualized. 
TABLE 2: The overlapping chemicals that are derived from different herbs in XXMD.

\begin{tabular}{|c|c|c|c|c|c|}
\hline Compound & Plant source & $\begin{array}{l}\text { Chemical } \\
\text { classification }\end{array}$ & Compound & Plant source & $\begin{array}{l}\text { Chemical } \\
\text { classification }\end{array}$ \\
\hline 1,8-Cineole & $\begin{array}{c}\text { Ephedrae Herba, Zingiberis } \\
\text { Rhizoma Recens }\end{array}$ & A & Bornylene & $\begin{array}{l}\text { Cinnamomi Ramulus, } \\
\text { Saposhnikoviae Radix }\end{array}$ & A \\
\hline 2-Nonanone & $\begin{array}{c}\text { Saposhnikoviae Radix, } \\
\text { Zingiberis Rhizoma Recens }\end{array}$ & A & Camphene & $\begin{array}{l}\text { Saposhnikoviae Radix root, } \\
\text { Zingiberis Rhizoma Recens }\end{array}$ & A \\
\hline 2-Nonenal & $\begin{array}{l}\text { Armeniacae Semen Amarum, } \\
\text { Saposhnikoviae Radix, }\end{array}$ & A & Camphor & $\begin{array}{l}\text { Armeniacae Semen Amarum, } \\
\text { Zingiberis Rhizoma Recens }\end{array}$ & $\mathrm{A}$ \\
\hline 3-Carene & $\begin{array}{c}\text { Chuanxiong Rhizoma, } \\
\text { Zingiberis Rhizoma Recens }\end{array}$ & A & Caryophyllene & $\begin{array}{l}\text { Armeniacae Semen Amarum, } \\
\text { Ginseng Radix et Rhizoma, } \\
\text { Zingiberis Rhizoma Recens }\end{array}$ & A \\
\hline Alloaeromadendrene & $\begin{array}{l}\text { Ginseng Radix et Rhizoma, } \\
\text { Zingiberis Rhizoma Recens }\end{array}$ & A & Citral & $\begin{array}{l}\text { Armeniacae Semen Amarum, } \\
\text { Zingiberis Rhizoma Recens }\end{array}$ & $\mathrm{A}$ \\
\hline Alpha-cadinene & $\begin{array}{c}\text { Chuanxiong Rhizoma, } \\
\text { Zingiberis Rhizoma Recens }\end{array}$ & A & $\begin{array}{l}\text { Gamma- } \\
\text { elemene }\end{array}$ & $\begin{array}{l}\text { Ginseng Radix et Rhizoma, } \\
\text { Zingiberis Rhizoma Recens }\end{array}$ & $\mathrm{A}$ \\
\hline Benzaldehyde & $\begin{array}{l}\text { Armeniacae Semen Amarum, } \\
\text { Cinnamomi Ramulus }\end{array}$ & A & Hexanal & $\begin{array}{l}\text { Armeniacae Semen Amarum, } \\
\text { Saposhnikoviae Radix }\end{array}$ & A \\
\hline Beta-bisabolene & $\begin{array}{l}\text { Ginseng Radix et Rhizoma, } \\
\text { Saposhnikoviae Radix, } \\
\text { Zingiberis Rhizoma Recens }\end{array}$ & A & Limonene & $\begin{array}{c}\text { Chuanxiong Rhizoma, Ephedrae } \\
\text { Herba }\end{array}$ & A \\
\hline Beta-elemene & $\begin{array}{l}\text { Armeniacae Semen Ginseng } \\
\text { Radix et Rhizoma, Zingiberis } \\
\text { Rhizoma Recens }\end{array}$ & A & Naphthaline & $\begin{array}{c}\text { Ephedrae Herba, Saposhnikoviae } \\
\text { Radix }\end{array}$ & A \\
\hline Beta-eudesmol & $\begin{array}{c}\text { Saposhnikoviae Radix, } \\
\text { Zingiberis Rhizoma Recens }\end{array}$ & A & Nonanaldehyde & $\begin{array}{l}\text { Armeniacae Semen Amarum, } \\
\text { Saposhnikoviae Radix root }\end{array}$ & A \\
\hline Borneol & $\begin{array}{l}\text { Armeniacae Semen Amarum, } \\
\text { Cinnamomi Ramulus, } \\
\text { Zingiberis Rhizoma Recens }\end{array}$ & A & Terpineol & $\begin{array}{c}\text { Ephedrae Herba, Zingiberis Rhizoma } \\
\text { Recens }\end{array}$ & A \\
\hline Eriodictyol & $\begin{array}{c}\text { Armeniacae Semen Amarum, } \\
\text { Scutellariae Radix }\end{array}$ & $\mathrm{B}$ & Caffeic acid & $\begin{array}{c}\text { Chuanxiong Rhizoma, Ephedrae } \\
\text { Herba }\end{array}$ & $\mathrm{E}$ \\
\hline Kaempferol & $\begin{array}{c}\text { Cinnamomi Ramulus, } \\
\text { Glycyrrhizae Radix et Rhizoma, } \\
\text { Paeoniae Radix Alba }\end{array}$ & B & Cinnamic acid & $\begin{array}{c}\text { Cinnamomi Ramulus, Ephedrae } \\
\text { Herba }\end{array}$ & $\mathrm{E}$ \\
\hline Quercetin & $\begin{array}{c}\text { Ephedrae Herba, Glycyrrhizae } \\
\text { Radix et Rhizoma }\end{array}$ & $\mathrm{B}$ & Folic acid & $\begin{array}{c}\text { Chuanxiong Rhizoma, Ginseng } \\
\text { Radix et Rhizoma }\end{array}$ & $\mathrm{E}$ \\
\hline Rutin & $\begin{array}{c}\text { Ephedrae Herba, Glycyrrhizae } \\
\text { Radix et Rhizoma }\end{array}$ & B & Malic acid & $\begin{array}{c}\text { Ephedrae Herba, Ginseng Radix et } \\
\text { Rhizoma }\end{array}$ & $\mathrm{E}$ \\
\hline Wogonin & $\begin{array}{l}\text { Saposhnikoviae Radix, } \\
\text { Scutellariae Radix }\end{array}$ & B & $\begin{array}{l}\text { Protocatechuic } \\
\text { acid }\end{array}$ & $\begin{array}{c}\text { Cinnamomi Ramulus, Chuanxiong } \\
\text { Rhizoma, Ephedrae Herba }\end{array}$ & $\mathrm{E}$ \\
\hline Choline & $\begin{array}{c}\text { Chuanxiong Rhizoma, Ginseng } \\
\text { Radix et Rhizoma }\end{array}$ & $\mathrm{C}$ & Daucosterol & $\begin{array}{l}\text { Aconiti Lateralis Radix Praeparata, } \\
\text { Ginseng Radix et Rhizoma, Paeoniae } \\
\text { Radix Alba, Saposhnikoviae Radix }\end{array}$ & $\mathrm{F}$ \\
\hline Chuanxiongzine & $\begin{array}{l}\text { Chuanxiong Rhizoma, } \\
\text { Ephedrae Herba }\end{array}$ & $\mathrm{C}$ & Panaxynol & $\begin{array}{l}\text { Ginseng Radix et Rhizoma, } \\
\text { Saposhnikoviae Radix }\end{array}$ & G \\
\hline Linoleic acid & $\begin{array}{c}\text { Ephedrae Herba, Stephaniae } \\
\text { Tetrandrae Radix }\end{array}$ & $\mathrm{D}$ & Beta-sitosterol & $\begin{array}{l}\text { Aconiti Lateralis Radix Praeparata, } \\
\text { Cinnamomi Ramulus, Paeoniae } \\
\text { Radix Alba, Saposhnikoviae Radix }\end{array}$ & $\mathrm{H}$ \\
\hline Palmitic acid & $\begin{array}{c}\text { Chuanxiong Rhizoma, } \\
\text { Ephedrae Herba, } \\
\text { Saposhnikoviae Radix, } \\
\text { Stephaniae Tetrandrae Radix }\end{array}$ & $\mathrm{D}$ & Campesterol & $\begin{array}{l}\text { Ginseng Radix et Rhizoma, } \\
\text { Scutellariae Radix }\end{array}$ & $\mathrm{H}$ \\
\hline
\end{tabular}

A: essential oil; B: flavonoid; C: alkaloid; D: saponin; E: phenol and organic acid; F: fatty acid and ester; G: polyacetylene; H: Steroid. 


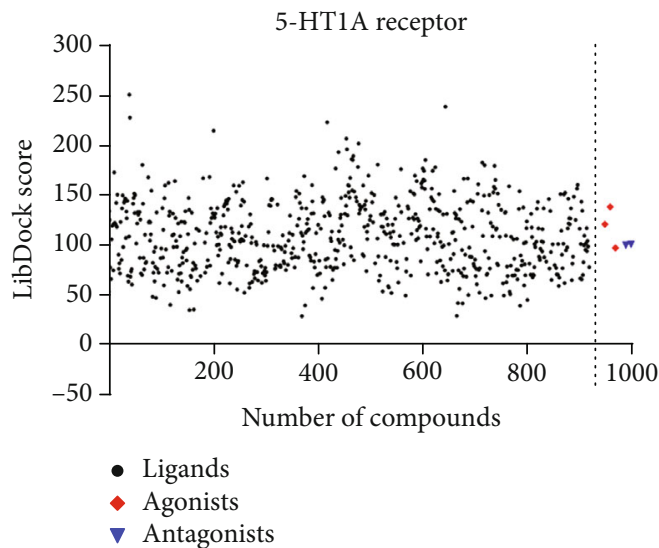

(a)

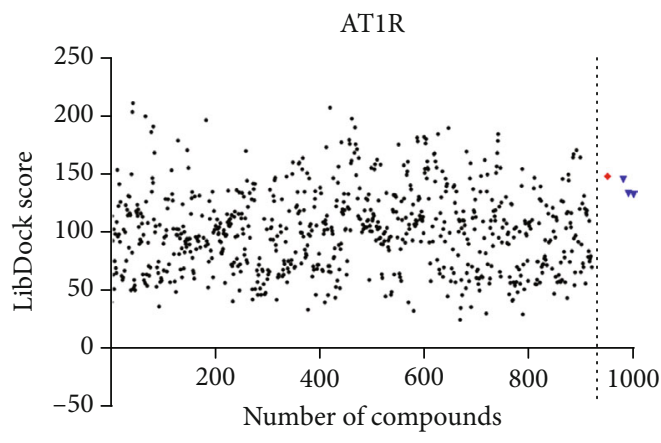

- Ligands

- Agonists

$\nabla$ Antagonists

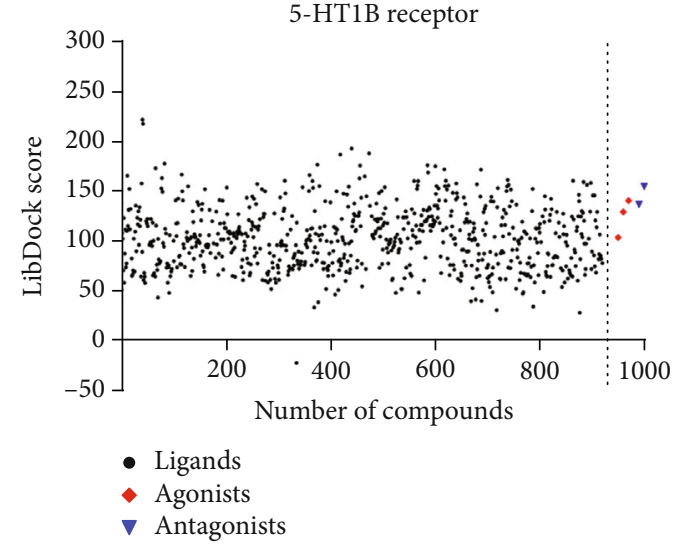

(b)

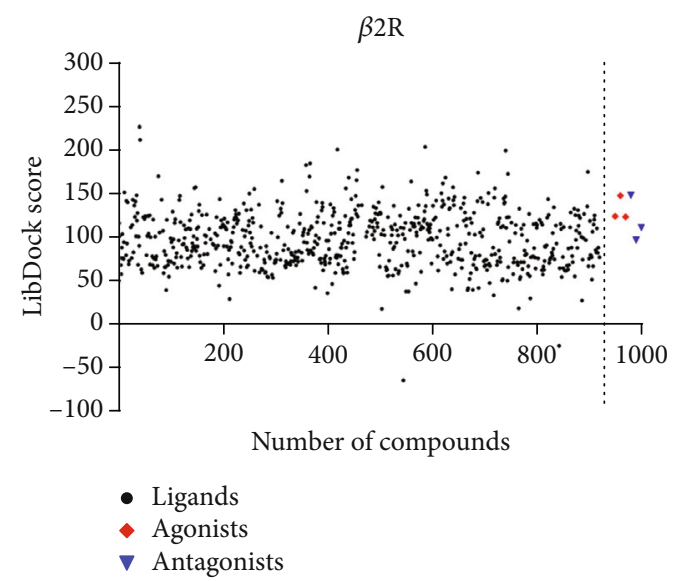

(d)

(c)

UTR

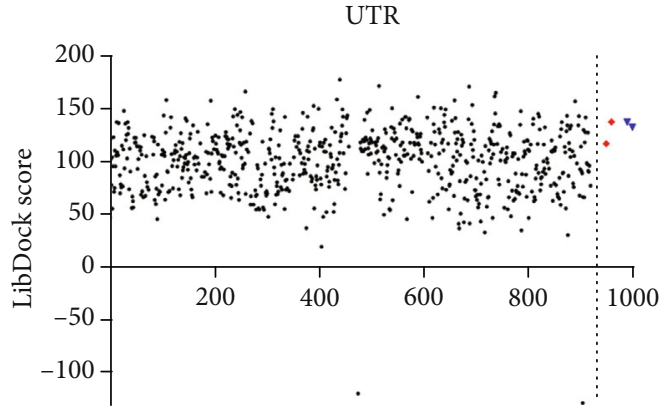

Number of compounds

- Ligands

- Agonists

$\nabla$ Antagonists

(e)

FIGURE 4: LibDock scores obtained by molecular docking of the chemical constituents of XXMD with the five vascular GPCR targets. The five vascular GPCR targets are (a) 5-HT1AR, (b) 5-HT1BR, (c) AT1R, (d) $\beta 2-\mathrm{AR}$, and (e) UTR.

\section{Results}

3.1. XXMD Induces Relaxation of Rat Basilar Artery Rings Precontracted by 5-HT. XXMD was found to induce relaxation of the rat basilar artery rings (Figure 1). The maximum relaxant effect of XXMD on the rings precontracted by 5 -HT was $97.13 \pm 2.74 \%$. The pEC50 value was $4.44 \pm 0.09$.
3.2. Construction and Analysis of the Compound Database of $X X M D$. In order to identify the potential material basis of the modulatory effects of XXMD on the vascular tone, $963 \mathrm{com}$ pounds from the twelve herbs of XXMD were retrieved from China Natural Product Database and from the literature. The number of compounds in each herb was determined, and the results are depicted in Figure 2. The compounds were 
TABLE 3: Overview of the LibDock scores of the chemical constituents of XXMD with the five vascular GPCRs.

\begin{tabular}{|c|c|c|c|c|c|}
\hline$\%$ & 5-HT1AR & 5-HT1BR & AT1R & $\beta 2-\mathrm{AR}$ & UTR \\
\hline Docked ratio & 76.52 & 84.46 & 84.89 & 76.96 & 78.70 \\
\hline$>$ positive mean ratio & 34.78 & 13.37 & 10.54 & 11.74 & 10.65 \\
\hline
\end{tabular}

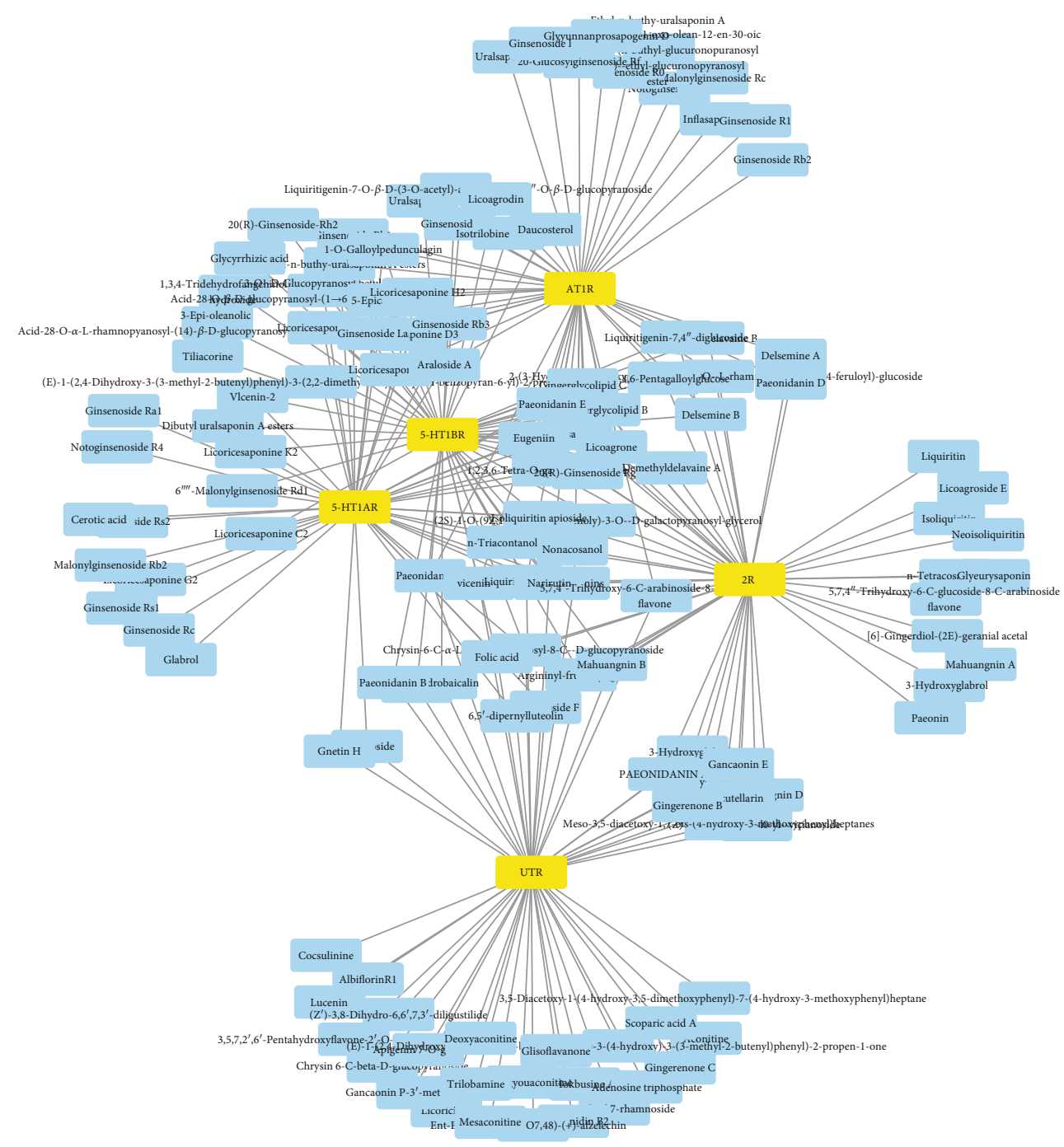

FIGURE 5: Compound-target interaction network of XXMD. The blue and yellow nodes represent the chemical constituents and targets, respectively, while the edges represent the interactions. The network was constructed and visualized using Cytoscape 3.7.1.

subsequently classified on the basis of their chemical structures, and the distribution of the compounds among the different chemical categories is provided in Table 1 and Figure 3. The results demonstrated that the five top-ranking chemical categories in the prescription were essential oils (32\%), flavonoids (24\%), alkaloids (13\%), saponins (7\%), phenols, and organic acids (5\%). However, it should be noted that the results reflect the number of different types of compounds rather than their abundance or relative content in the prescription.

In order to identify the potentially effective constituents of XXMD, the compounds derived from the different herbs of XXMD were retrieved and analyzed. The names, plant sources, and chemical categories of forty compounds are enlisted in Table 2. Of the compounds that were derived from multiple plant sources, the majority were essential oils, flavonoids, phenols, or organic acids. This result was consistent with the data pertaining to the major chemical constituents of XXMD.

3.3. Molecular Docking of Ligands to Vascular GPCR Targets. The cocrystallized ligands were redocked to the five vascular GPCR targets (5-HT1AR, 5-HT1BR, AT1R, $\beta 2-A R$, and UTR) using the LibDock program in Discovery Studio 4.1. 


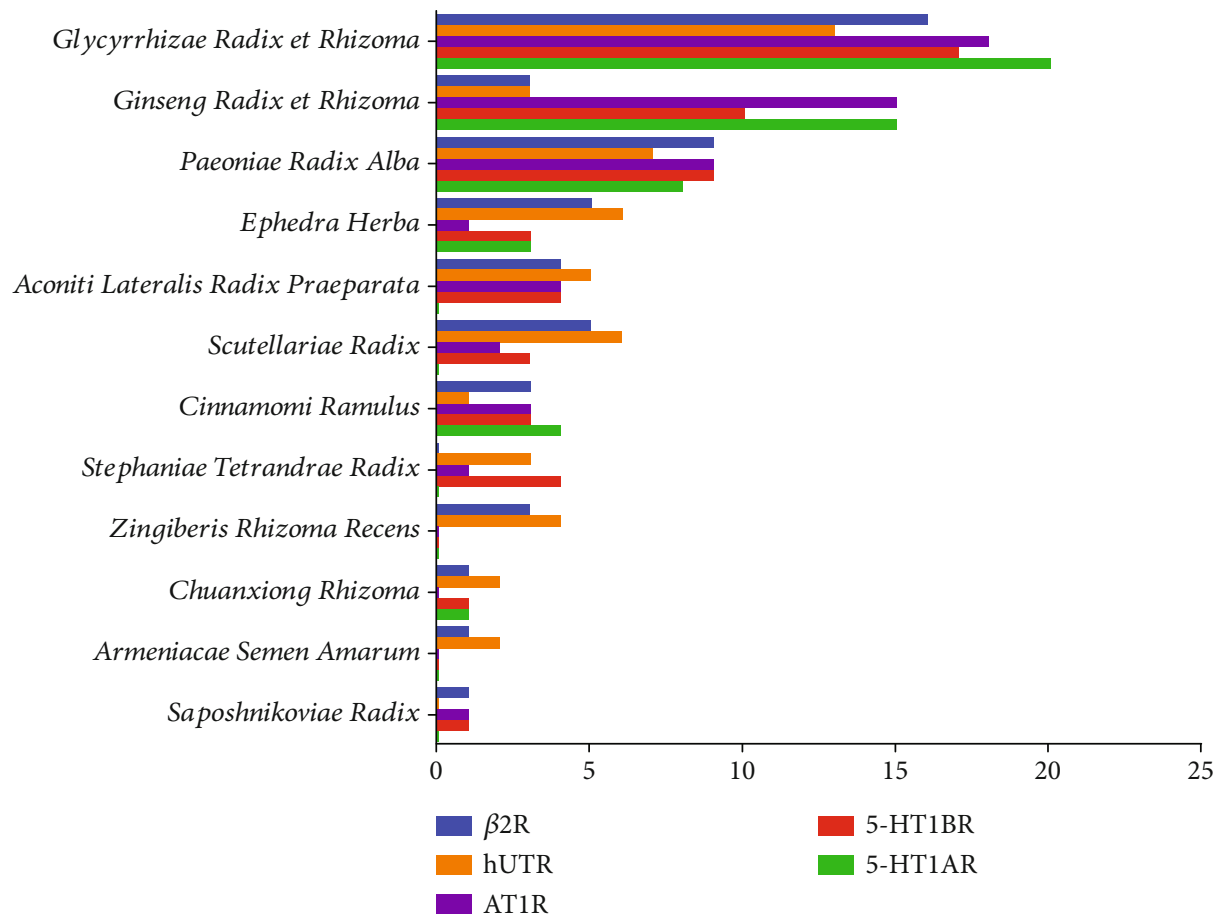

FIGURE 6: Enrichment of the 50 top-scoring compounds with high docking scores with each of the vascular GPCR targets, classified according to their herbal source in XXMD.

The ligands dihydroergotamine, 5,7-diethyl-1-\{[2'-(1H-tetrazol-5-yl) biphenyl-4-yl]methyl\}-3,4-dihydro-1,6-naphthyridin$2(1 \mathrm{H})$-one, and BI167107 were extracted from the crystal structures of 5-HT1BR, AT1R, and $\beta 2-\mathrm{AR}$, respectively, and redocked into the active site of the corresponding receptors. The root mean square deviation (RMSD) values between the docked poses and the ligand conformation in the crystallographic complexes were $0.3074,0.3168$, and $0.4324 \AA$, which indicated that the docking protocol was highly accurate and reliable.

For each GPCR target, the compounds with the highest scores were selected to generate a scatter diagram, as depicted in Figure 4. The LibDock scores of the agonists and antagonists of the GPCR targets are provided in Figure 4. Most of the chemical constituents of XXMD could be successfully docked to the target GPCRs. For each GPCR, some of the compounds exhibited higher LibDock scores than the agonists and antagonists, indicating their strong binding affinity to the GPCR targets. Nevertheless, some of the compounds failed to dock to the target GPCRs owing to their structural characteristics.

In order to analyze the overall results of ligand-receptor docking, we determined the number of compounds that were successfully docked and the percentage of compounds with LibDock scores higher than the average scores of the agonists and antagonists. As demonstrated in Table 3, 76.52\%, $84.46 \%, 84.89 \%, 76.96 \%$, and $78.70 \%$ of the compounds in XXMD successfully docked to 5-HT1AR, 5-HT1BR, AT1R, $\beta 2-A R$, and UTR, respectively. Additionally, more than $10 \%$ of the compounds of XXMD had higher LibDock scores than the average score of the GPCR agonists and antagonists.

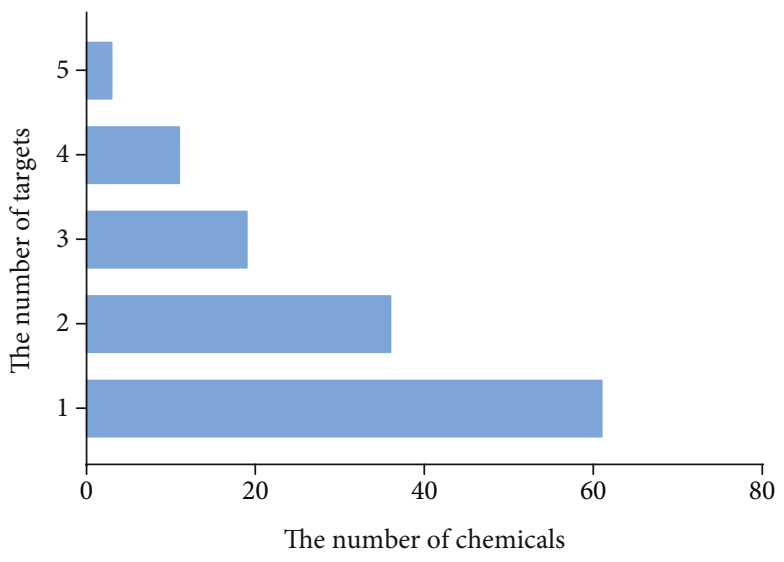

FIgURE 7: The number of top 50 scoring compounds that interacted with multiple vascular GPCR targets.

Therefore, these results suggested that most of the compounds of XXMD have the potential to bind and interact with the five vascular GPCRs considered herein. It subsequently follows that the vascular tone can be comprehensively modulated by XXMD via the interactions between the multiple chemical constituents of XXMD and the different vascular GPCR targets in the compound-target network.

3.4. Construction and Analysis of Compound-Target Interaction Network of XXMD. In order to elucidate the material basis of the modulation of vascular tone by XXMD, the 50 top-scoring compounds that targeted the vascular GPCRs were selected, and the compound-target network of 
TABLE 4: The compounds in XXMD that interacted with multiple targets.

\begin{tabular}{|c|c|c|c|}
\hline No. & Compounds & Source & $\begin{array}{c}\text { The number } \\
\text { of targets }\end{array}$ \\
\hline 1 & Gallotannins & Paeoniae Radix Alba & 5 \\
\hline 2 & Liquiritin apioside & Glycyrrhizae Radix et Rhizoma & 5 \\
\hline 3 & Narirutin & Glycyrrhizae Radix et Rhizoma & 5 \\
\hline 4 & 1,2,3,4,6-Pentagalloylglucose & Paeoniae Radix Alba & 4 \\
\hline 5 & 20(R)-Ginsenoside Rg2 & Ginseng Radix et Rhizoma & 4 \\
\hline 6 & $\begin{array}{l}\text { Chrysin-6-C- } \alpha \text {-L-arabinopyranosyl-8-C- } \beta \text {-D- } \\
\text { glucopyranoside }\end{array}$ & Scutellariae Radix & 4 \\
\hline 7 & Eugeniin & Paeoniae Radix Alba & 4 \\
\hline 8 & Folic acid & Ginseng Radix et Rhizoma, Chuanxiong Rhizoma & 4 \\
\hline 9 & Gingerglycolipid B & Cinnamomi Ramulus & 4 \\
\hline 10 & Gingerglycolipid C & Cinnamomi Ramulus & 4 \\
\hline 11 & Licoagrone & Glycyrrhizae Radix et Rhizoma & 4 \\
\hline 12 & Inflasaponin IV & Glycyrrhizae Radix et Rhizoma & 4 \\
\hline 13 & Paeonidanin $\mathrm{C}$ & Paeoniae Radix Alba & 4 \\
\hline 14 & Paeonidanin E & Paeoniae Radix Alba & 4 \\
\hline 15 & $\begin{array}{l}\text { (2S)-1-O-(9Z,12Z-Octadeeadienoly)-3-O- } \beta-\mathrm{D}- \\
\text { galactopyranosyl-glycerol }\end{array}$ & Cinnamomi Ramulus & 3 \\
\hline 16 & $1,2,3,6$-Tetra-O-gafloyl- $\beta$-D-glucose & Paeoniae Radix Alba & 3 \\
\hline 17 & 1-O-Galloylpedunculagin & Paeoniae Radix Alba & 3 \\
\hline 18 & $\begin{array}{l}\text { 2-(3-Hydroxy-4-methoxyphenyl)-ethyl-1-O- } \alpha \text {-L- } \\
\text { rhamnosyl-( }(\longrightarrow 3)-\beta \text {-D-(4-feruloyl)-glucoside }\end{array}$ & Scutellariae Radix & 3 \\
\hline 19 & $\begin{array}{l}\text { 3-O- } \beta \text {-D-Glucopyranosyl betulinic acid-28-O- } \beta \text {-D- } \\
\text { glucopyranosyl- }(1 \longrightarrow 6)-\beta \text {-D-glucopyranoside }\end{array}$ & Ginseng Radix et Rhizoma & 3 \\
\hline 20 & $\begin{array}{l}\text { 5,7,4" -Trihydroxy-6-C-arabinoside-8-C-glucoside } \\
\text { flavone }\end{array}$ & Scutellariae Radix & 3 \\
\hline 21 & 6,5'-dipernylluteolin & Glycyrrhizae Radix et Rhizoma & 3 \\
\hline 22 & Argininyl-fructosyl-glucose & Ginseng Radix et Rhizoma & 3 \\
\hline 23 & Delsemine B & Aconiti Lateralis Radix Praeparata & 3 \\
\hline 24 & Demethyldelavaine B & Aconiti Lateralis Radix Praeparata & 3 \\
\hline 25 & Ginsenoside Rb1 & Ginseng Radix et Rhizoma & 3 \\
\hline 26 & Isoliquiritin apioside & Glycyrrhizae Radix et Rhizoma & 3 \\
\hline 27 & Licoagroside F & Glycyrrhizae Radix et Rhizoma & 3 \\
\hline 28 & Licoricesaponine F3 & Glycyrrhizae Radix et Rhizoma & 3 \\
\hline 29 & Liquiritigenin- $7,4^{\prime \prime}$-diglucoside & Glycyrrhizae Radix et Rhizoma & 3 \\
\hline 30 & Mahuangnin B & Ephedrae Herba & 3 \\
\hline 31 & Methyl-n-buthy-uralsaponin A esters & Glycyrrhizae Radix et Rhizoma & 3 \\
\hline 32 & $\mathrm{n}$-Triacontanol & Ephedrae Herba & 3 \\
\hline 33 & Vicenin-2 & Glycyrrhizae Radix et Rhizoma, Ephedrae Herba & 3 \\
\hline 34 & (Z)-(1S,5R)- $\beta$-Pinen-10-yl- $\beta$-vicianoside & Paeoniae Radix Alba & 2 \\
\hline 35 & 3-Hydroxyglabrol II & Glycyrrhizae Radix et Rhizoma & 2 \\
\hline 36 & 5-Epicatechin & Cinnamomi Ramulus & 2 \\
\hline 37 & 6'-Malonylginsenoside $\mathrm{Rd} 1$ & Ginseng Radix et Rhizoma & 2 \\
\hline 38 & Amygdalin & Armeniacae semen Amarum & 2 \\
\hline 39 & Araloside A & Ginseng Radix et Rhizoma & 2 \\
\hline 40 & Daucosterol & $\begin{array}{l}\text { Ginseng Radix et Rhizoma, Paeoniae Radix Alba, } \\
\text { Saposhnikoviae Radix, Aconiti Lateralis Radix Praeparata }\end{array}$ & 2 \\
\hline 41 & Delsemine A & Aconiti Lateralis Radix Praeparata & 2 \\
\hline 42 & Demethyldelavaine A & Aconiti Lateralis Radix Praeparata & 2 \\
\hline
\end{tabular}


TABLE 4: Continued.

\begin{tabular}{|c|c|c|c|}
\hline No. & Compounds & Source & $\begin{array}{l}\text { The number } \\
\text { of targets }\end{array}$ \\
\hline 43 & Dibutyl uralsaponin A esters & Glycyrrhizae Radix et Rhizoma & 2 \\
\hline 44 & Dihydrobaicalin & Scutellariae Radix & 2 \\
\hline 45 & Gancaonin E & Glycyrrhizae Radix et Rhizoma & 2 \\
\hline 46 & Gingerenone B & Zingiberis Rhizoma Recens & 2 \\
\hline 47 & Ginsenoside La & Ginseng Radix et Rhizoma & 2 \\
\hline 48 & Ginsenoside Rb3 & Ginseng Radix et Rhizoma & 2 \\
\hline 49 & Ginsenoside Rg3 & Paeoniae Radix Alba & 2 \\
\hline 50 & Glycyroside & Glycyrrhizae Radix et Rhizoma & 2 \\
\hline 51 & Gnetin $\mathrm{H}$ & Paeoniae Radix Alba & 2 \\
\hline 52 & Isotrilobine & Stephaniae Tetrandrae Radix & 2 \\
\hline 53 & Isotrilobine- $\mathrm{N}$-2-oxide & Stephaniae Tetrandrae Radix & 2 \\
\hline 54 & Licoagrodin & Glycyrrhizae Radix et Rhizoma & 2 \\
\hline 55 & Licoricesaponine A3 & Glycyrrhizae Radix et Rhizoma & 2 \\
\hline 56 & Licoricesaponine C2 & Glycyrrhizae Radix et Rhizoma & 2 \\
\hline 57 & Licoricesaponine D3 & Glycyrrhizae Radix et Rhizoma & 2 \\
\hline 58 & Licoricesaponine $\mathrm{H} 2$ & Glycyrrhizae Radix et Rhizoma & 2 \\
\hline 59 & Licoricesaponine $\mathrm{K} 2$ & Glycyrrhizae Radix et Rhizoma & 2 \\
\hline 60 & $\begin{array}{c}\text { Liquiritigenin-7-O- } \beta \text {-D-(3-O-acetyl)-apiofuranosyl- } 4^{\prime \prime} \\
\text {-O- } \beta \text {-D-glucopyranoside }\end{array}$ & Glycyrrhizae Radix et Rhizoma & 2 \\
\hline 61 & Mahuangnin D & Ephedrae Herba & 2 \\
\hline 62 & $\begin{array}{l}\text { Meso-3,5-diacetoxy-1,7-bis-(4-hydroxy-3- } \\
\text { methoxyphenyl)heptanes }\end{array}$ & Zingiberis Rhizoma Recens & 2 \\
\hline 63 & Nonacosanol & Ephedrae Herba & 2 \\
\hline 64 & Paeonidanin A & Paeoniae Radix Alba & 2 \\
\hline 65 & Paeonidanin B & Paeoniae Radix Alba & 2 \\
\hline 66 & Paeonidanin D & Paeoniae Radix Alba & 2 \\
\hline 67 & Scutellarin & Scutellariae Radix & 2 \\
\hline 68 & Uralsaponin A & Glycyrrhizae Radix et Rhizoma & 2 \\
\hline 69 & Vlcenin-2 & Glycyrrhizae Radix et Rhizoma & 2 \\
\hline
\end{tabular}

XXMD was constructed using Cytoscape version 3.7.1. As depicted in Figure 5, the blue and yellow nodes represent the chemical components and targets, respectively, while the edges represent the interactions. The network analyzer plugin of Cytoscape was used to analyze the network by calculating the number of nodes, network density, and network heterogeneity, among other factors. The compound-target network comprised 249 edges, 135 nodes, 130 compounds (after removal of duplicates), and 5 targets. Network analysis revealed that multiple compounds targeted the same GPCR, while some of the compounds had multiple targets, which demonstrated that the perspective of CHM is very different from the philosophy of WCM, which considers that one compound interacts with one specific target.

In order to explore the relationships between the chemical constituents of the twelve herbs of XXMD and the five vascular GPCR targets, the 50 top-scoring compounds with the highest docking scores were selected for each of the targets and categorized according to their herbal sources (Figure 6). The three major herbs were Glycyrrhizae Radix et Rhizoma, Ginseng Radix et Rhizoma, and Paeoniae Radix Alba.
The compound-target network interactions were subsequently analyzed. Several of the 50 top-scoring compounds interacted with multiple targets, including 5-HT1AR, 5HT1BR, AT1R, $\beta 2$-AR, and UTR. As depicted in Figure 7 and Table 4, 3 compounds of XXMD, namely, gallotannin, liquiritin apioside, and narirutin, interacted with all the five GPCRs, while 11 compounds, including 1,2,3,4,6-pentagalloylglucose and folic acid, interacted with 4 targets. On the other hand, 19 compounds, including ginsenoside Rb1, interacted with 3 GPCR targets, and 36 compounds interacted with 2 of the GPCR targets. The binding modes of gallotannin, liquiritin apioside, and nariutin in the binding sites of the GPCR targets (5-HT1AR, 5-HT1BR, AT1R, $\beta 2$-AR, and UTR) are depicted in Figure 8, Figure 9, and Figure 10, respectively.

\section{Discussion}

To date, there are no definitive treatment strategies for ischemic stroke. With the development of recent research on multi-component-multi-target drugs, the functions of TCM 


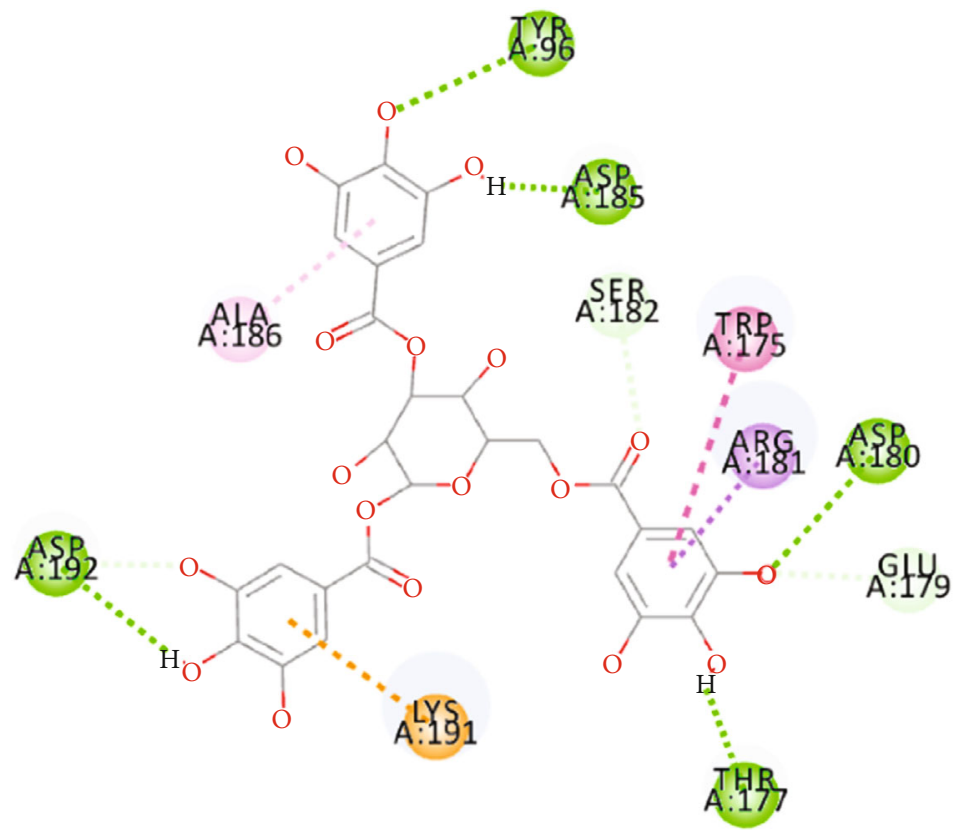

Interactions

Conventional hydrogen bond

$\square$ Carbon hydrogen bond

Pi-cation

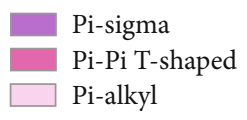

(a)

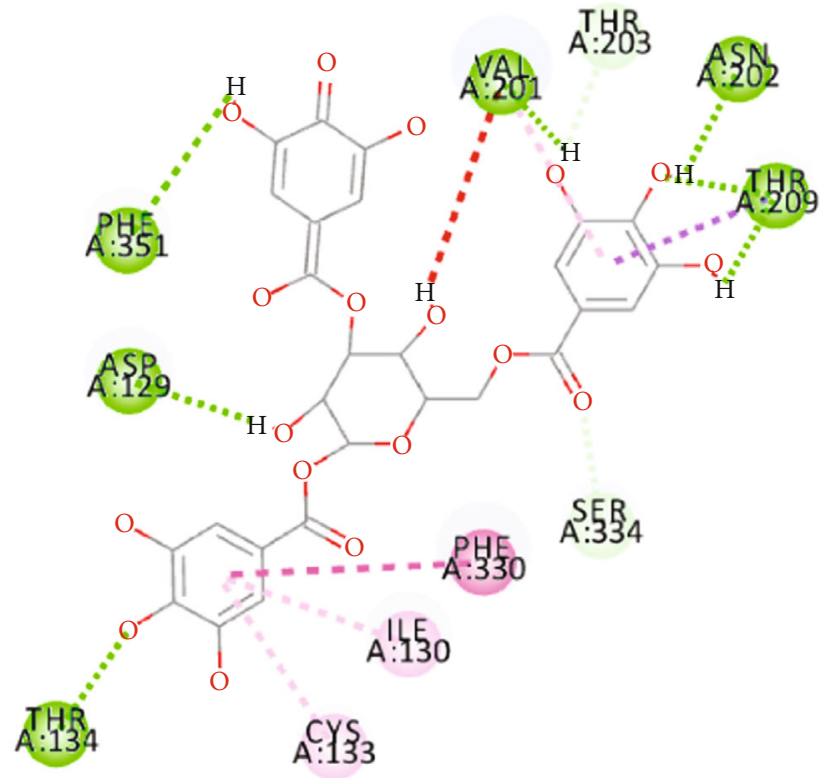

Interactions

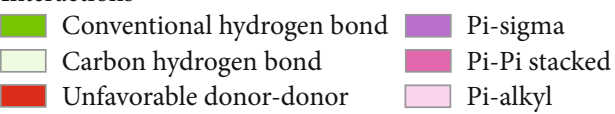

(b)

Figure 8: Continued. 


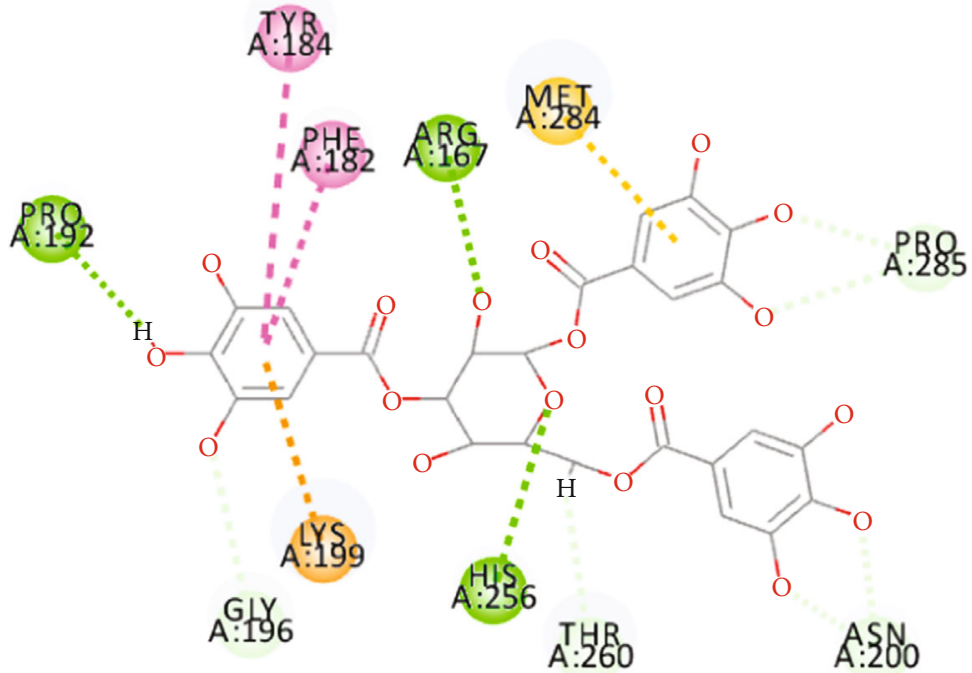

Interactions

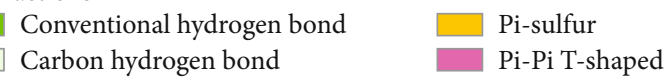

(c)

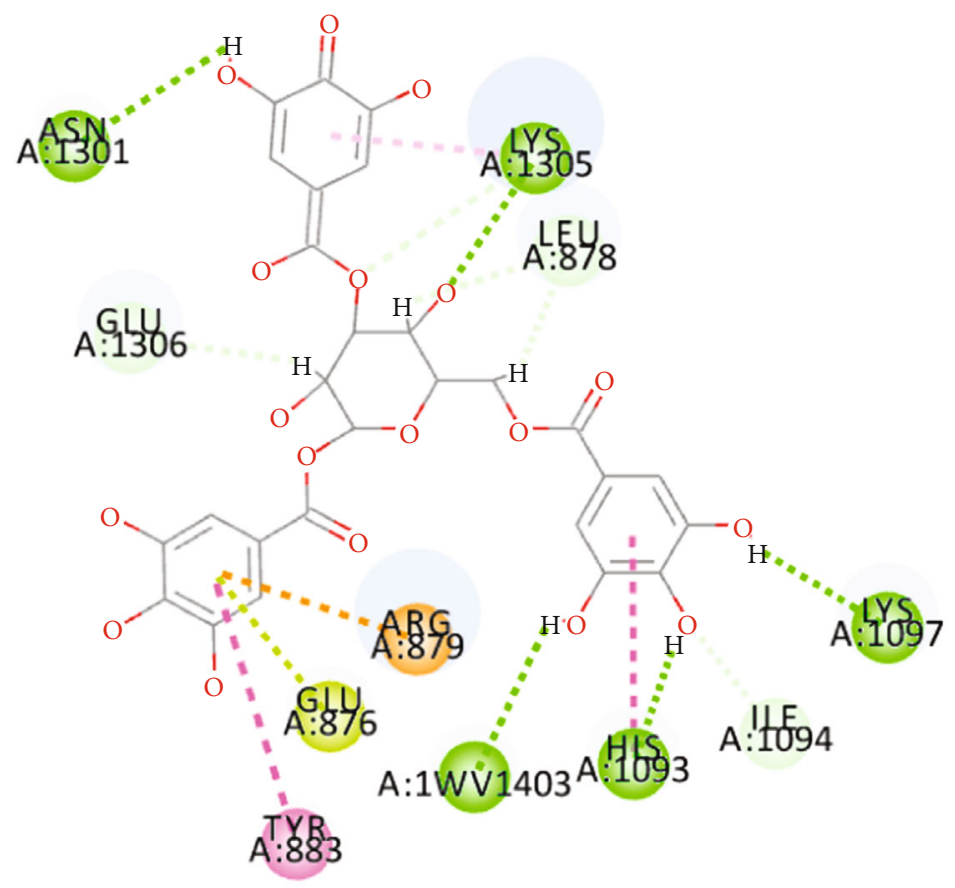

Interactions

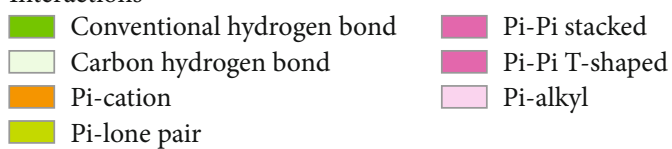

(d)

FIGURE 8: Continued. 

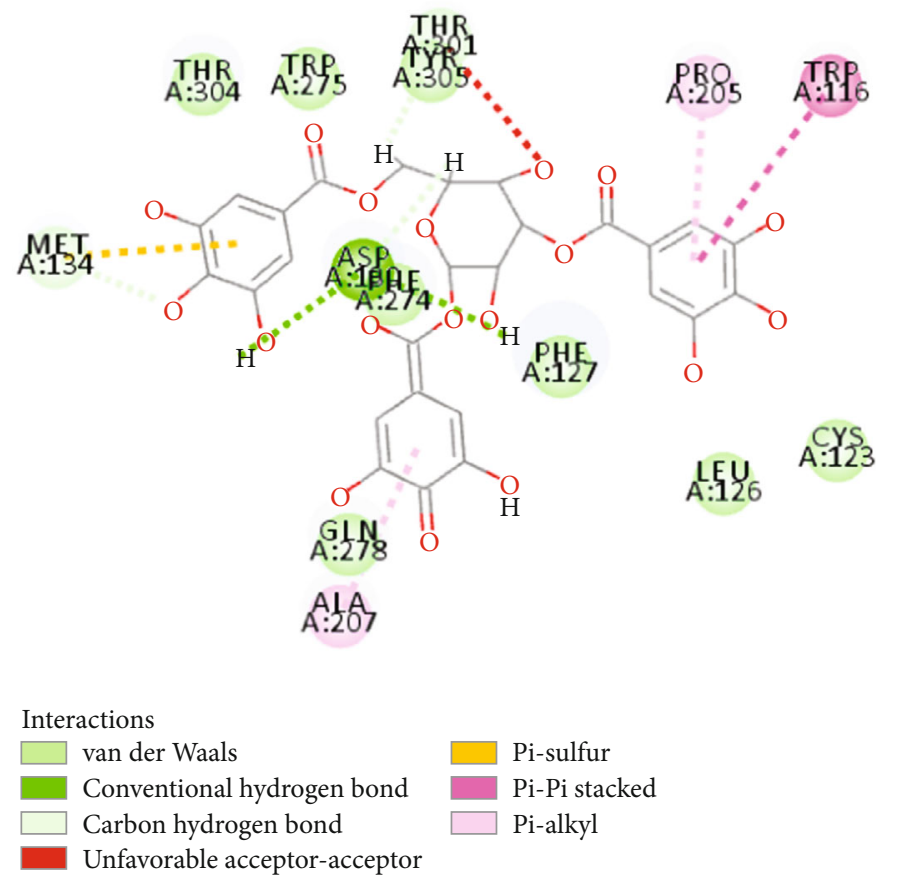

(e)

Figure 8: The binding modes of gallotannin in the ligand-binding site of (a) 5-HT1AR, (b) 5-HT1BR, (c) AT1R, (d) $\beta 2$-AR, and (e) UTR.

in the treatment of complex diseases have become increasingly important. Owing to the potent compound group formulation used in TCM prescriptions, the efficacy of TCM is attributed to the interactions between multiple active ingredients and multiple disease targets. Several animal experiments and clinical studies have demonstrated that XXMD, a CHM with relaxant effects on cerebral blood vessels, can improve the treatment outcomes in both acute and chronic ischemic brain injury $[4,5,10]$. By relaxing the cerebral blood vessels, XXMD can restore the supply of blood and nutrients to the ischemic area, providing a material basis of the prevention of reperfusion injury and neuronal protection.

In this study, the vasorelaxant effects of XXMD on rat basilar arteries contracted by 5 -HT were determined. The modulation of vascular tone and the process of cerebral ischemia are mediated via the interactions between GPCRs and their ligands, including 5-HT, Ang II, and UII. Therefore, molecular docking was performed to determine the potential synergistic effects of the components of XXMD on the regulation of vascular tone via modulation of the activity of vascular GPCRs. First, a database of 963 compounds of XXMD, with different chemical structures, was constructed and analyzed. Molecular docking was used to investigate the interactions between the chemical constituents of XXMD and the five vascular GPCRs, namely, 5-HT1AR, 5-HT1BR, AT1R, $\beta 2-A R$, and UTR. The 50 top-scoring compounds with high docking scores to each of the GPCR targets were selected and sorted. The herbal sources of these compounds were determined for identifying the roles of the twelve herbs of XXMD in regulating the vascular tone via modulation of GPCR activity.
The results of our study suggested that several overlapping compounds and their analogues are widely distributed in the different medicinal herbs of XXMD. The contents of these ingredients are relatively high in the XXMD prescription, compared to those of the other compounds. Furthermore, previous studies have demonstrated that most of these compounds have similar physiological activities, including antitumor, anti-inflammatory, antioxidative, neuroprotective, blood lipid-regulating, and vasorelaxant properties. These compounds, derived from a variety of different plants in XXMD, have different chemical structures and can produce synergistic therapeutic effects under the same pathological conditions. Therefore, they are likely to be the key components that play a crucial role in the therapeutic effect of XXMD.

Apart from their pharmacological activities, some of the chemical ingredients, including essential oils, promote the absorption of other drugs. It is speculated that ginger is indispensable in the treatment of cerebral apoplexy by XXMD, and the maximum dosage should be five Liang [32]. Furthermore, it has been demonstrated that ginger extract improves memory deficits and neuronal density in rats with focal cerebral ischemia [33]. It can therefore be concluded that the essential oils, which are the main chemical components of ginger, are likely to enhance the absorption of other constituents in several CHMs.

Classification of the herbal sources of the 50 top-scoring compounds revealed that the three major herbs were Glycyrrhizae Radix et Rhizoma, Ginseng Radix et Rhizoma, and Paeoniae Radix Alba. The therapeutic potential of these herbs and their constituents in cerebral ischemia has been 

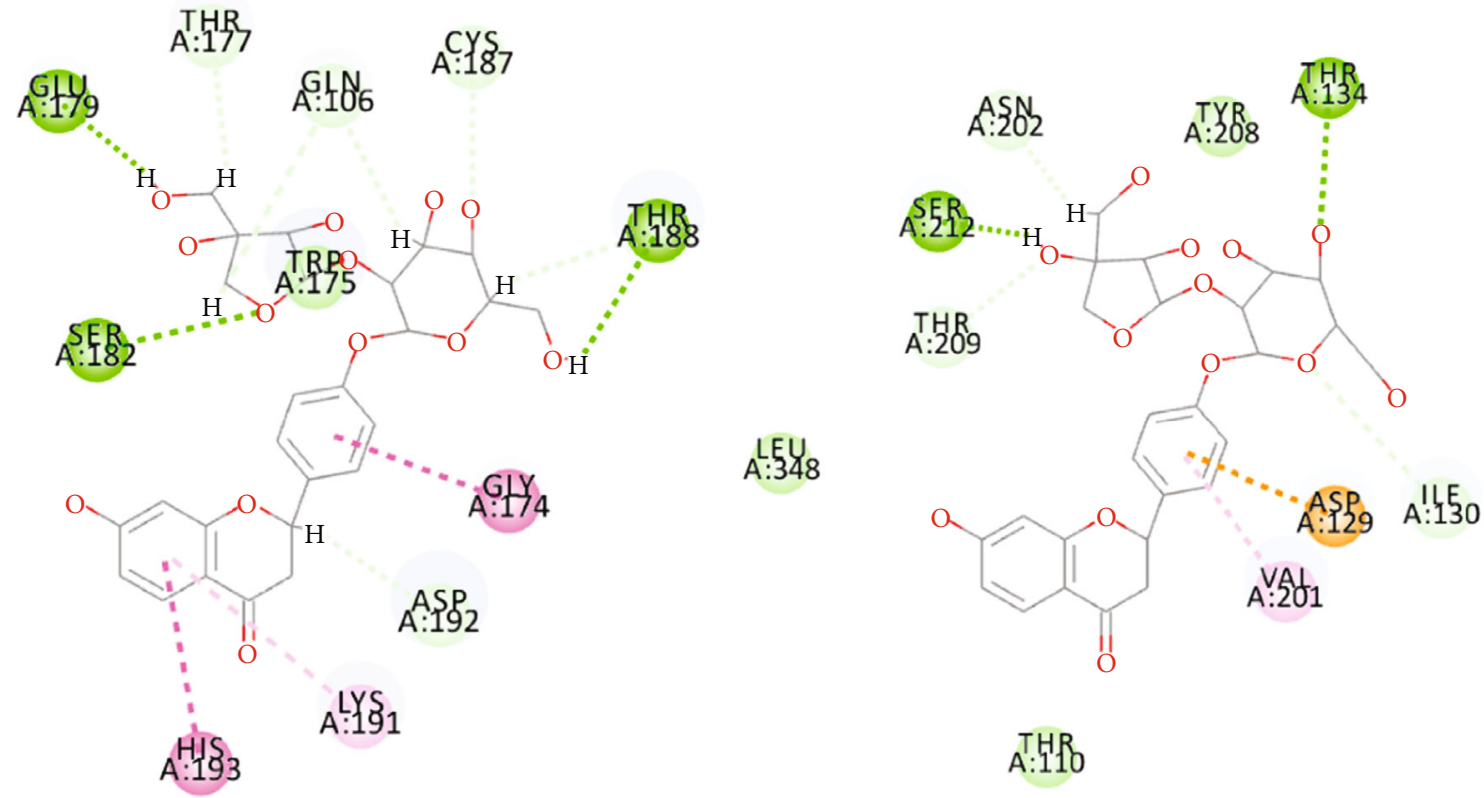

\section{Interactions \\ $\square$ van der Waals
Conventional hydrogen bond \\ Carbon hydrogen bond}

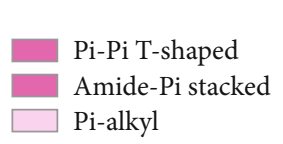

(a)

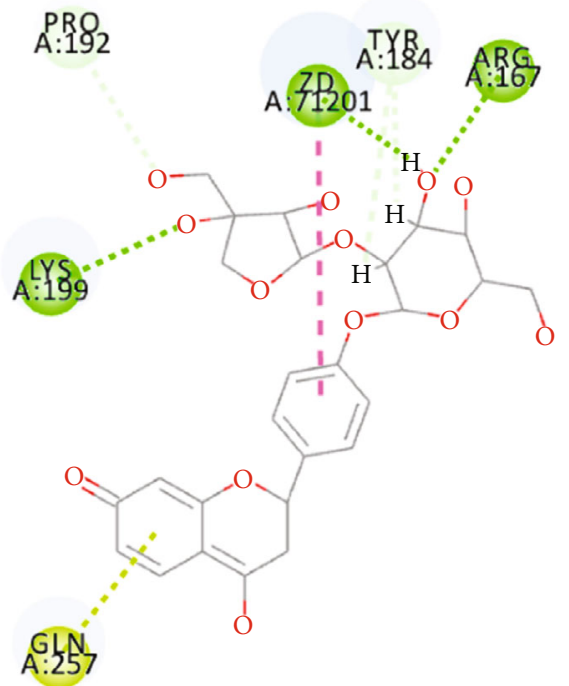

Interactions

Conventional hydrogen bond

$\square$ Carbon hydrogen bond

$\square$ Pi-lone pair

Pi-Pi stacked

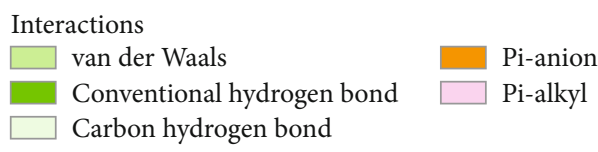

(b)

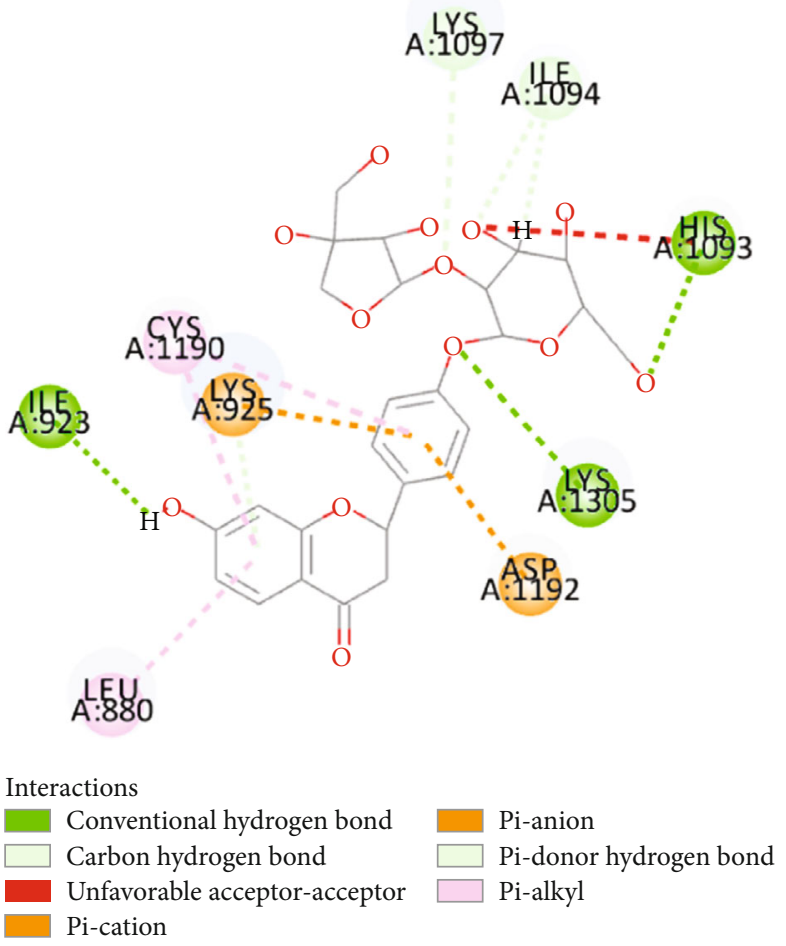

(c)

(d)

FIgURE 9: Continued. 

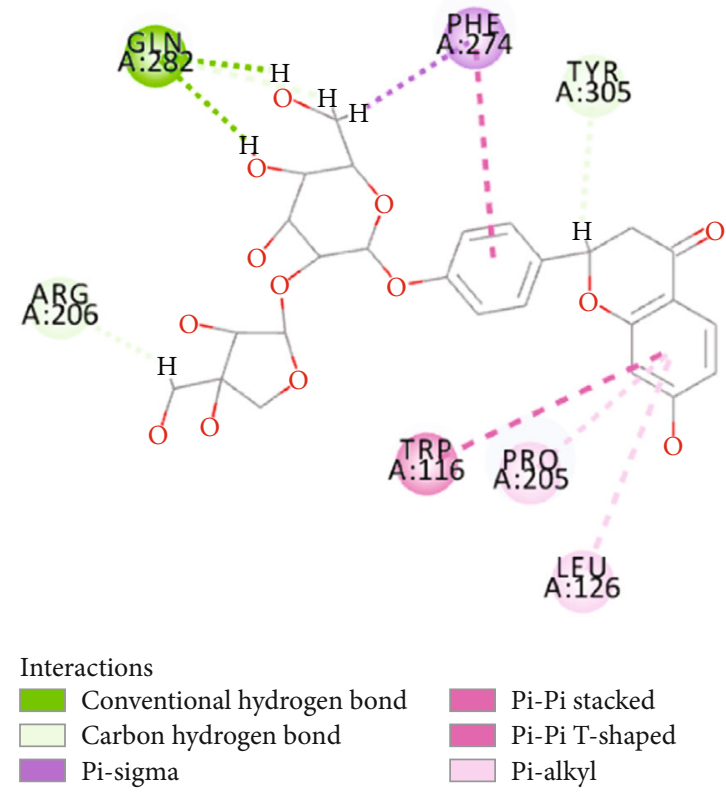

(e)

FIGURE 9: The binding modes of liquiritin apioside in the ligand-binding site of (a) 5-HT1AR, (b) 5-HT1BR, (c) AT1R, (d) $\beta 2$-AR, and (e) UTR.

extensively studied. It has been demonstrated that the aqueous extract of licorice (Glycyrrhizae Radix et Rhizoma) reduces infarct volumes and exerts a neuroprotective effect by regulating the expression of apoptosis-related proteins in mice with middle cerebral artery occlusion (MCAO) [34]. Glycyrrhizin (GL) [35] and 18 $\beta$-glycyrrhetinic acid (GA) [36], isolated from the roots of licorice, have also been reported to have neuroprotective effects in focal cerebral ischemia/reperfusion brain injury, which are mediated via the anti-inflammatory, antioxidant, and antiapoptotic effects of GL, or the strong antioxidant and radical scavenging properties of GA in global cerebral ischemia/reperfusion brain injury. Isoliquiritigenin (ISL), a flavonoid present in the roots of licorice, is known to have vasorelaxant effects and protects against injury due to cerebral ischemia by ameliorating cerebral energy metabolism and via its antioxidant properties [37]. Ginsenoside Rd, belonging to the class of Ginseng Radix et Rhizoma compounds in herbal medicine, has been shown to attenuate damage due to ischemic stroke via suppression of oxidative stress and inflammation [38]. The active metabolite of ginsenosides in the gut, 20(S)-protopanaxadiol, induces vasorelaxation in isolated rat thoracic aorta via an endothelium-independent pathway [39]. A combination of Paeoniae Radix Alba and Rhizoma Ligustici Chuanxiong was reported to ameliorate focal cerebral ischemia in rats with MCAO by attenuating the endoplasmic reticulum stress-dependent apoptotic signaling pathway [40]. Therefore, the results of this study indicate that Glycyrrhizae Radix et Rhizoma, Ginseng Radix et Rhizoma, and Paeoniae Radix Alba play a key role in the modulatory effect of XXMD on vascular tone and its effects on suppressing ischemic stroke via regulation of the compound-target interaction network in XXMD and necessitate further investigation.
It has been reported that TCM influences disease progression by modulating GPCR activity. The Chinese herbal formula, Sini Tang (SNT), comprises Glycyrrhizae Radix et Rhizoma, Aconiti Lateralis Radix Praeparata, and Zingiberis Rhizoma Recens. SNT improves cardiac function by inhibiting the excessive activation of the renin-angiotensinaldosterone system, which involves a reduction in the levels of plasma angiotensin II and downregulation of the protein and gene levels of AT1R in heart failure after myocardial infarction in rats [41]. ISL has also been reported to exhibit in vitro 5-HT2B receptor antagonistic activity [42]. Ginsenoside $\mathrm{Rb} 1$ has been reported to possess antidepressant-like activity, which is mediated via the modulation of $5-\mathrm{HT}_{2 \mathrm{~A}}$ receptors [43]. The results of our study demonstrated that XXMD inhibited the constriction of rat basil artery induced by 5 -HT. However, the effects of XXMD on vasoconstriction induced by other GPCR ligands, and the underlying mechanism involving the modulation of GPCRs and their signaling pathways, necessitate further investigation.

By reviewing the relevant literature, we found that most of the components of XXMD that target multiple vascular GPCRs possess vasorelaxant effects and suppress ischemic stroke. For instance, 1,2,3,4,6-pentagalloylglucose, a major component of Paeoniae Radix Alba, binds to 4 vascular GPCR targets and has been reported to induce vasorelaxation and suppress the vascular inflammatory process by activating the NO/cGMP signaling pathway [44]. Folic acid, a member of the vitamin B complex, and isolated from Ginseng Radix et Rhizoma and Chuanxiong Rhizoma, was found to bind to 4 GPCR targets. Interestingly, folic acid has been reported to improve endothelial function [45] and alleviate various microglia-mediated neuroinflammation via the Notch1/nuclear factor kappa B p65 pathway in the hippocampus 

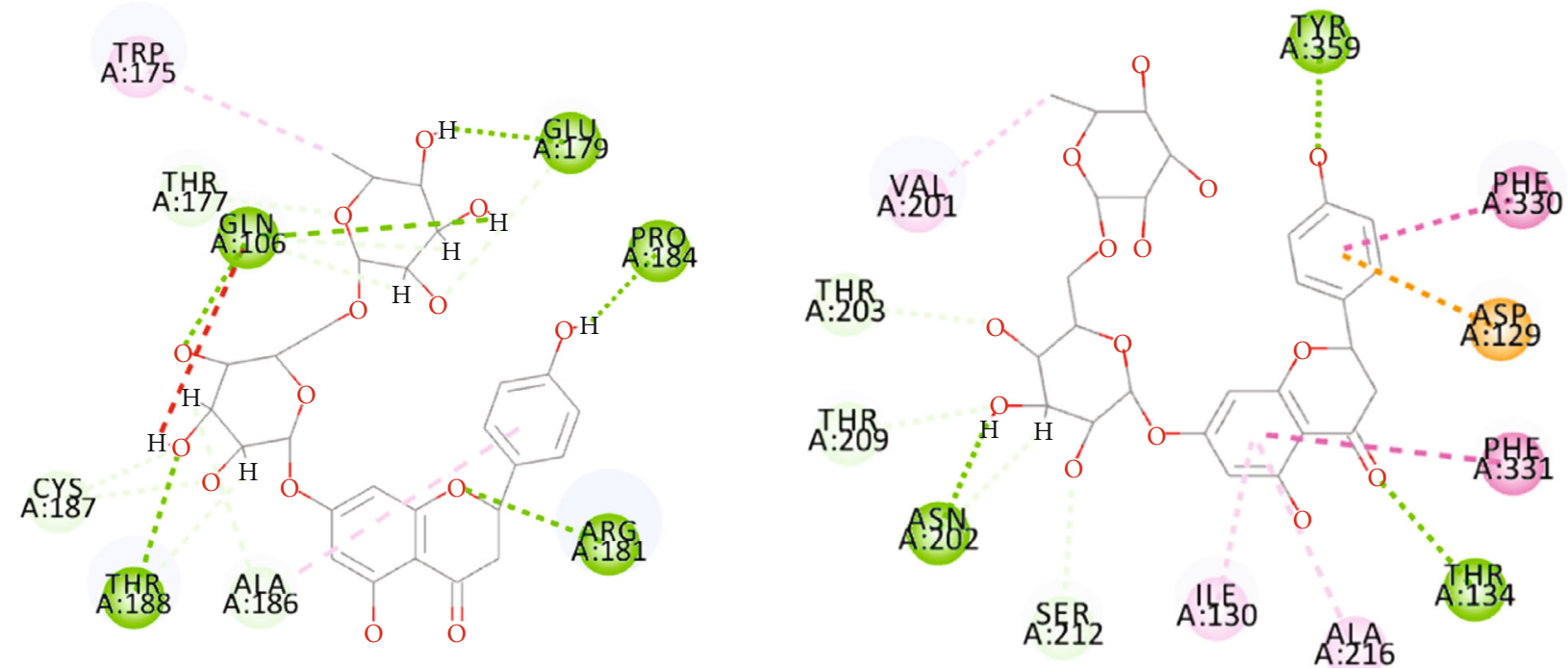

Interactions

Conventional hydrogen bond

Carbon hydrogen bond

Unfavorable donor-donor Pi-alkyl

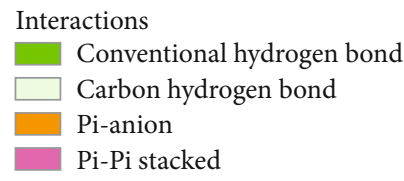

$\square$ Conventional hydrogen bond
Carbon hydrogen bond
Pi-anion
Pi-Pi stacked

(b)

(a)

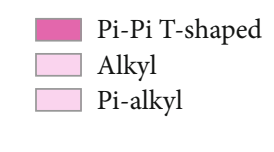

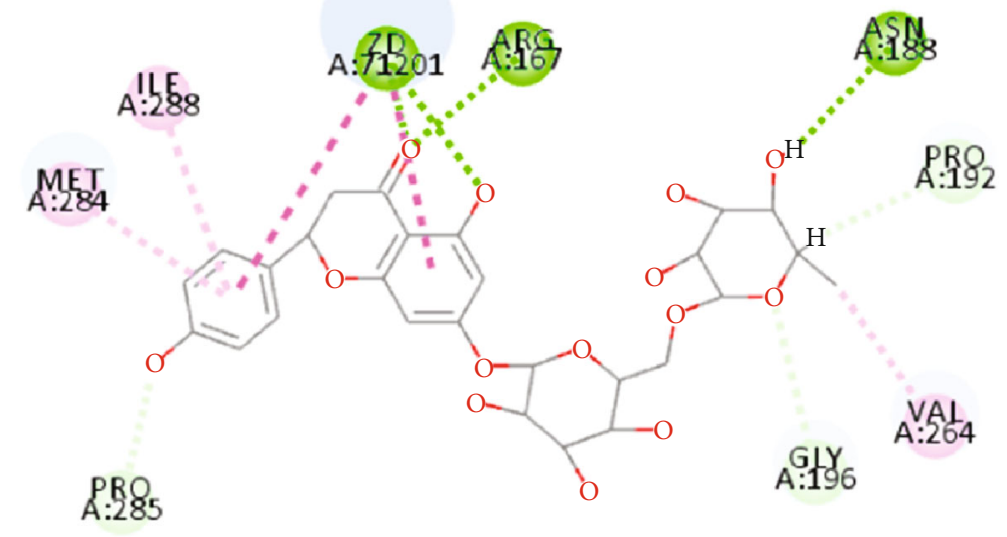

Interactions

Conventional hydrogen bond

Carbon hydrogen bond

Alkyl

Pi-Pi stacked

(c)

Figure 10: Continued. 

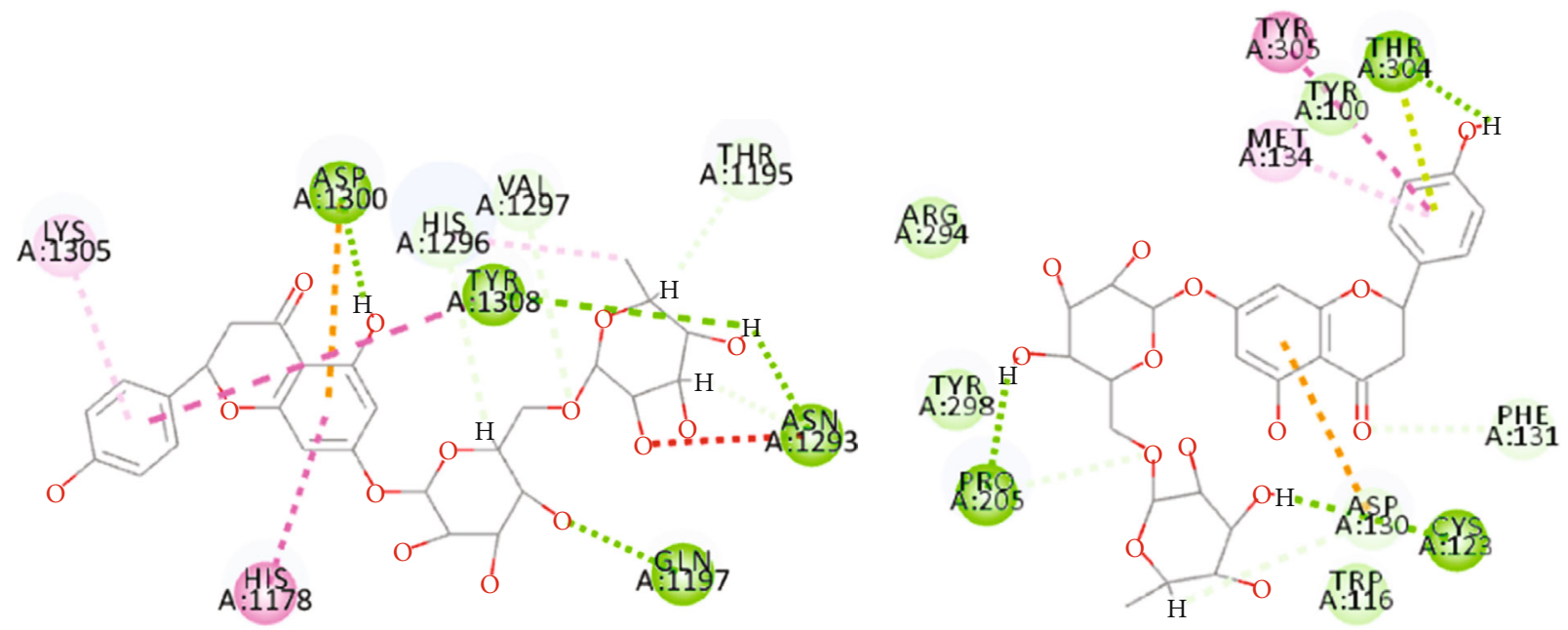

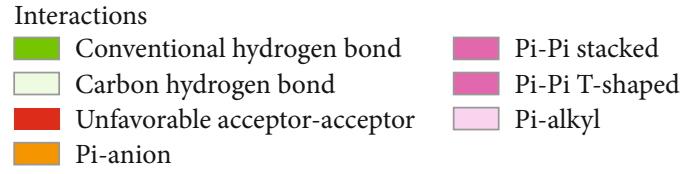

(d)

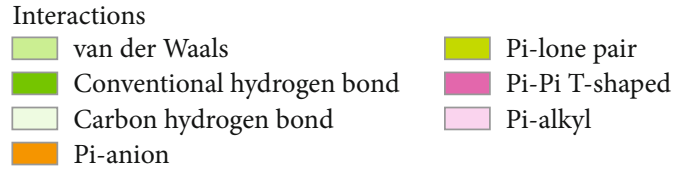

(e)

FIGURE 10: The binding modes of nariutin in the ligand-binding site of (a) 5-HT1AR, (b) 5-HT1BR, (c) AT1R, (d) $\beta 2$-AR, and (e) UTR.

following brain I/R injury in rats [46]. Ginsenoside Rb1, an active component extracted from Ginseng Radix et Rhizoma, was found to bind to three GPCR targets and has been reported to promote poststroke axonal regeneration by activating the cAMP/PKA/CREB signaling pathway [47]. Few studies have investigated the vasorelaxant and anti-ischemic stroke effects of the three compounds of XXMD, namely, gallotannin, liquiritin apioside, and narirutin, which bound to all the five vascular GPCR targets. It is therefore necessary to study the effects of these three compounds in further detail. The results of our study demonstrate that the compounds that targeted the vascular GPCRs could mediate the modulatory effect of XXMD on vascular tone and provide a material basis of the treatment of ischemic stroke with XXMD. However, the results of this study need to be verified using experiments and data validation.

In conclusion, the current study clearly demonstrated that XXMD was able to relax the cerebral artery rings of rats. XXMD comprises numerous compounds with different chemical structures and is derived from multiple plant sources. Therefore, XXMD might regulate cerebrovascular function via the network of interactions between the constituents of XXMD and the GPCRs involved in vasoconstriction. Our results demonstrated that the various herbal constituents of XXMD contribute to the regulation of vascular tone via the modulation of the target GPCRs. By investigating and analyzing the monomeric component of XXMD from the perspective of chemical composition and the relationships between the chemical constituents and targets, we were able to provide evidence for understanding the mechanisms underlying the effect of XXMD in the treatment of stroke.

\section{Data Availability}

The data used to support the findings of this study are included within the article. Other data are available from the corresponding author upon request.

\section{Conflicts of Interest}

These authors have no conflict of interest to declare.

\section{Authors' Contributions}

Yanjia Shen and Ran Yang are co-first authors.

\section{Acknowledgments}

This work was supported by grants from the National Key Research and Development Plan (2016YFC1000905), CAMS Innovation Fund for Medical Sciences (CIFMS) (2016-I2M-3-007 and 2017-I2M-1-010), Major Scientific and Technological Special Project for "Significant New Drug Creation" (2013ZX09508104, 2018ZX09711001-003-005, 2018ZX09711001-001-014, and 2018ZX09711001-010), the National Natural Science Foundation of China (81473383 and 81773935), and the China Scholarship Council (201808110107).

\section{References}

[1] D. L. Fu, L. Lu, W. Zhu et al., "Xiaoxuming decoction for acute ischemic stroke: a systematic review and meta-analysis," Journal of Ethnopharmacology, vol. 148, no. 1, pp. 1-13, 2013. 
[2] X. L. He, Y. H. Wang, H. L. Qin, B. M. Gang, and G. H. Du., "Effect of active components of Chinese herbal medicine Xiaoxuming decoction on oxidative stress and neuronal apoptosis in rats with chronic cerebral ischemia [J]," Chinese Journal of Neuromedicine, vol. 11, no. 12, pp. 1214-1218, 2012.

[3] X. H. Zhu, S. J. Li, H. H. Hu, L. R. Sun, M. Das, and T. M. Gao, "Neuroprotective effects of xiao-xu-ming decoction against ischemic neuronal injury in vivo and in vitro," Journal of Ethnopharmacology, vol. 127, no. 1, pp. 38-46, 2010.

[4] R. Lan, Y. Zhang, J. Xiang et al., "Xiao-Xu-Ming decoction preserves mitochondrial integrity and reduces apoptosis after focal cerebral ischemia and reperfusion via the mitochondrial p 53 pathway," Journal of Ethnopharmacology, vol. 151, no. 1, pp. 307-316, 2014.

[5] X. Du, C. Lu, X. L. He, and G. H. Du, "Effects of active components group of Xiaoxuming decoction on brain mitochondria in cerebral ischemia/reperfusion rats during early recovery period," China journal of Chinese materia medica, vol. 42, no. 11, pp. 2139-2145, 2017.

[6] Y. H. Wang, X. L. He, H. G. Yang, H. L. Qin, and G. H. Du, "Effects of the effective components group of Xiaoxuming decoction on MCAO rats [J]," Chinese Pharmaceutical Journal, vol. 47, no. 3, pp. 194-198, 2012.

[7] R. Lan, J. Xiang, G. H. Wang et al., "Xiao-Xu-Ming decoction protects against blood-brain barrier disruption and neurological injury induced by cerebral ischemia and reperfusion in rats," Evidence-based Complementary and Alternative Medicine, vol. 2013, Article ID 629782, 2013.

[8] R. Lan, J. Xiang, Y. Zhang et al., "PI3K/Akt pathway contributes to neurovascular unit protection of Xiao-Xu-Ming decoction against focal cerebral ischemia and reperfusion injury in rats," Evidence-based Complementary and Alternative Medicine, vol. 2013, Article ID 459467, 2013.

[9] Y. H. Wang, X. L. He, H. G. Yang, H. L. Qin, and G. H. du, "Effects of the active components of Chinese herbal medicine Xiaoxuming decoction on memory behavior and brain injury in rats with chronic cerebral ischemia," Zhong $\mathrm{Xi} \mathrm{Yi}$ Jie $\mathrm{He}$ Xue Bao, vol. 10, no. 1, pp. 91-99, 2012.

[10] Y. H. Wang, Y. L. Yang, X. Cheng, J. Zhang, W. Li, and G. H. du, "Xiao-Xu-Ming decoction extract regulates differentially expressed proteins in the hippocampus after chronic cerebral hypoperfusion," Neural Regeneration Research, vol. 14, no. 3, pp. $470-479,2019$.

[11] C. Iadecola, M. S. Buckwalter, and J. Anrather, "Immune responses to stroke: mechanisms, modulation, and therapeutic potential," The Journal of Clinical Investigation, vol. 130, no. 6, pp. 2777-2788, 2020.

[12] X. Hu, T. M. De Silva, J. Chen, and F. M. Faraci, "Cerebral vascular disease and neurovascular injury in ischemic stroke," Circulation Research, vol. 120, no. 3, pp. 449-471, 2017.

[13] G. Kauffenstein, I. Laher, K. Matrougui, N. C. Guerineau, and D. Henrion, "Emerging role of $\mathrm{G}$ protein-coupled receptors in microvascular myogenic tone," Cardiovascular Research, vol. 95, no. 2, pp. 223-232, 2012.

[14] N. M. Barnes, G. P. Ahern, C. Becamel et al., "International Union of Basic and Clinical Pharmacology. CX. Classification of receptors for 5-hydroxytryptamine; pharmacology and function," Pharmacological Reviews, vol. 73, no. 1, pp. 310-520, 2021.

[15] Y. Yu, H. Jiang, Y. Niu et al., "Candesartan inhibits inflammation through an angiotensin II type 1 receptor independent way in human embryonic kidney epithelial cells," Anais da Academia Brasileira de Ciências, vol. 91, no. 2, 2019.
[16] H. Vaudry, J. Leprince, D. Chatenet et al., "International Union of Basic and Clinical Pharmacology. XCII. Urotensin II, Urotensin II-Related Peptide, and Their Receptor: From Structure to Function," Pharmacological Reviews, vol. 67, no. 1, pp. 214-258, 2015.

[17] M. Komara, R. Vasudevan, P. Ismail, S. A. Bakar, S. R. Pishva, and F. Heidari, "Association of beta 2 adrenoceptor gene polymorphisms in Malaysian hypertensive subjects," Genetics and molecular research: GMR, vol. 13, no. 2, pp. 2939-2948, 2014.

[18] S. M. Kim, L. Chen, R. Faulhaber-Walter et al., "Regulation of Renin Secretion and Expression in Mice Deficient in $\beta 1$ - and $\beta 2$-Adrenergic Receptors," Hypertension, vol. 50, no. 1, pp. 103-109, 2007.

[19] C. H. Lee, J. H. Ahn, and M. H. Won, "New expression of 5HT1A receptor in astrocytes in the gerbil hippocampal CA1 region following transient global cerebral ischemia," Neurological sciences: official journal of the Italian Neurological Society and of the Italian Society of Clinical Neurophysiology, vol. 36, no. 3, pp. 383-389, 2015.

[20] A. Justin, S. Divakar, and M. Ramanathan, "Cerebral ischemia induced inflammatory response and altered glutaminergic function mediated through brain AT 1 and not AT 2 receptor," Biomedicine \& Pharmacotherapy, vol. 102, pp. 947-958, 2018.

[21] J. Chuquet, C. Lecrux, D. Chatenet et al., "Effects of urotensinII on cerebral blood flow and ischemia in anesthetized rats," Experimental Neurology, vol. 210, no. 2, pp. 577-584, 2008.

[22] L. F. Chen and J. S. Wu, "The effect of Xiao-xu-ming decoction on thrombus and cerebral blood vessel [J]," Pharmacology and Clinics of Chinese Materia Medica, vol. 7, no. 6, p. 4, 1991.

[23] L. F. Chen and X. H. Wang, "Effect of Xiao-xu-ming decoction on cerebral vascular permeability and pathological changes of brain tissue after cerebral ischemia in rats," Pharmacology and Clinics of Chinese Materia Medica, vol. 13, no. 6, pp. 4-9, 1997.

[24] Y. Y. Ye and J. X. Shang, "Study on the mechanism of cerebral edema in hemorrhagic apoplexy with Xiao-xu-ming decoction [J]," Chinese Journal of Experimental Traditional Medical Formulae, vol. 3, pp. 48-49, 1999.

[25] A. L. Hopkins, "Network pharmacology: the next paradigm in drug discovery," Nature Chemical Biology, vol. 4, no. 11, pp. 682-690, 2008.

[26] S. Li and B. Zhang, "Traditional Chinese medicine network pharmacology: theory, methodology and application," Chinese Journal of Natural Medicines, vol. 11, no. 2, pp. 110-120, 2013.

[27] L. G. Ferreira, R. N. Dos Santos, G. Oliva, and A. D. Andricopulo, "Molecular docking and structure-based drug design strategies," Molecules, vol. 20, no. 7, pp. 13384-13421, 2015.

[28] X. J. Li, D. X. Kong, and H. Y. Zhang, "Chemoinformatics approaches for traditional Chinese medicine research and case application in anticancer drug discovery," Current Drug Discovery Technologies, vol. 7, no. 1, pp. 22-31, 2010.

[29] C. Wang, Z. Jia, Z. Wang et al., "Pharmacokinetics of 21 active components in focal cerebral ischemic rats after oral administration of the active fraction of Xiao-Xu-Ming decoction," Journal of Pharmaceutical and Biomedical Analysis, vol. 122, pp. 110-117, 2016.

[30] T. Y. Yuan, Y. Yan, Y. J. Wu et al., "Vasodilatory effect of a novel Rho-kinase inhibitor, DL0805-2, on the rat mesenteric artery and its potential mechanisms," Cardiovascular Drugs and Therapy, vol. 28, no. 5, pp. 415-424, 2014. 
[31] H. M. Berman, J. Westbrook, Z. Feng et al., "The Protein Data Bank," Nucleic Acids Research, vol. 28, no. 1, pp. 235-242, 2000.

[32] X. H. Zhu, S. Y. Chen, and T. M. Gao, "Xiaoxuming decoction and stroke: a literature-based study [J]," Journal of First Military Medical University, vol. 22, no. 6, pp. 546-565, 2002.

[33] J. Wattanathorn, J. Jittiwat, T. Tongun, S. Muchimapura, and K. Ingkaninan, "Zingiber officinale mitigates brain damage and improves memory impairment in focal cerebral ischemic rat," Evidence-based Complementary and Alternative Medicine, vol. 2011, Article ID 429505, 2011.

[34] C. Lim, S. Lim, B. Lee, B. Kim, and S. Cho, "Licorice pretreatment protects against brain damage induced by middle cerebral artery occlusion in mice," Journal of Medicinal Food, vol. 21, no. 5, pp. 474-480, 2018.

[35] G. Gong, L. Xiang, L. Yuan et al., "Protective effect of glycyrrhizin, a direct HMGB1 inhibitor, on focal cerebral ischemia/reperfusion-induced inflammation, oxidative stress, and apoptosis in rats," PLoS One, vol. 9, no. 3, article e89450, 2014.

[36] M. N. Oztanir, O. Ciftci, A. Cetin, M. A. Durak, N. Basak, and Y. Akyuva, "The beneficial effects of $18 \beta$-glycyrrhetinic acid following oxidative and neuronal damage in brain tissue caused by global cerebral ischemia/reperfusion in a C57BL/J6 mouse model," Neurological sciences: official journal of the Italian Neurological Society and of the Italian Society of Clinical Neurophysiology, vol. 35, no. 8, pp. 1221-1228, 2014.

[37] C. Zhan and J. Yang, "Protective effects of isoliquiritigenin in transient middle cerebral artery occlusion-induced focal cerebral ischemia in rats," Pharmacological Research, vol. 53, no. 3, pp. 303-309, 2006.

[38] R. Ye, Q. Yang, X. Kong et al., "Ginsenoside Rd attenuates early oxidative damage and sequential inflammatory response after transient focal ischemia in rats," Neurochemistry International, vol. 58, no. 3, pp. 391-398, 2011.

[39] L. Gan, Z. H. Wang, H. Zhang et al., "Endothelium-independent vasorelaxant effect of 20(S)-protopanaxadiol on isolated rat thoracic aorta," Acta Pharmacologica Sinica, vol. 37, no. 12, pp. 1555-1562, 2016.

[40] J. Gu, J. Chen, N. Yang et al., "Combination of Ligusticum chuanxiong and Radix Paeoniae ameliorate focal cerebral ischemic in MCAO rats via endoplasmic reticulum stressdependent apoptotic signaling pathway," Journal of Ethnopharmacology, vol. 187, pp. 313-324, 2016.

[41] Y. Zhu, J. Zhao, Q. Han et al., "The effect and mechanism of Chinese herbal formula Sini Tang in heart failure after myocardial infarction in rats," Evidence-based Complementary and Alternative Medicine, vol. 2018, Article ID 5629342, 7 pages, 2018.

[42] C. Yamada, Y. Saegusa, K. Nakagawa et al., "Rikkunshito, a Japanese kampo medicine, ameliorates decreased feeding behavior via ghrelin and serotonin $2 \mathrm{~B}$ receptor signaling in a novelty stress murine model," BioMed Research International, vol. 2013, Article ID 792940, 9 pages, 2013.

[43] N. Yamada, H. Araki, and H. Yoshimura, "Identification of antidepressant-like ingredients in ginseng root (Panax ginseng C.A. Meyer) using a menopausal depressive-like state in female mice: participation of 5-HT2A receptors," Psychopharmacology, vol. 216, no. 4, pp. 589-599, 2011.

[44] D. G. Kang, M. K. Moon, D. H. Choi, J. K. Lee, T. O. Kwon, and H. S. Lee, "Vasodilatory and anti-inflammatory effects of the 1,2, 3, 4, 6-penta-O-galloyl- $\beta$-d-glucose (PGG) via a nitric oxide-cGMP pathway," European Journal of Pharmacology, vol. 524, no. 1-3, pp. 111-119, 2005.
[45] A. E. Stanhewicz and W. L. Kenney, "Role of folic acid in nitric oxide bioavailability and vascular endothelial function," Nutrition Reviews, vol. 75, no. 1, pp. 61-70, 2017.

[46] M. Cheng, L. Yang, Z. Dong et al., "Folic acid deficiency enhanced microglial immune response via the Notch1/nuclear factor kappa B p65 pathway in hippocampus following rat brain I/R injury and BV2 cells," Journal of Cellular and Molecular Medicine, vol. 23, no. 7, pp. 4795-4807, 2019.

[47] X. Gao, X. Zhang, L. Cui et al., "Ginsenoside Rb1 promotes motor functional recovery and axonal regeneration in poststroke mice through cAMP/PKA/CREB Signaling pathway," Brain Research Bulletin, vol. 154, pp. 51-60, 2020. 